\title{
Avaliação do conforto térmico e renovação de ar em ambientes com chaminés solares
}

\author{
Evaluation of thermal comfort and air changes in indoor \\ environments with solar chimneys
}

\begin{abstract}
Matheus Menezes Oliveira Joyce Correna Carlo

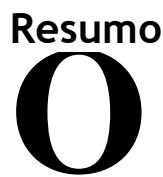

uso de estratégias relacionadas à ventilação natural para garantir conforto térmico e renovação de ar é necessário em grande parte do território brasileiro. Nesse contexto, as chaminés solares promovem benefícios como o aumento das trocas de ar e do conforto dos usuários. Este artigo tem como objetivo investigar a capacidade de um modelo de chaminé solar proporcionar conforto e renovação de ar em salas de aula e escritórios. Foram realizadas duas etapas de simulações termoenergéticas no EnergyPlus: a primeira avaliou parâmetros como altura, número de dispositivos instalados por ambiente e orientação solar para proporcionar mais horas em conforto e renovação de ar para quatro cidades brasileiras; a segunda ampliou o escopo dos dispositivos/ambientes simulados para oito cidades brasileiras, com uso dos melhores parâmetros identificados. A variação dos climas na segunda avaliação apresentou um impacto de até $80 \%$ nas horas em conforto. A influência do dispositivo proporcionou um aumento médio de $28 \%$ no conforto nas salas de aula e $21 \%$ nos escritórios. Foram observadas taxas de renovação de ar média entre 2,4 e 13,5 trocas/hora. Os melhores resultados foram observados nas cidades da ZB1, ZB2, ZB3, ZB4 e ZB5, o que torna essas zonas bioclimáticas potencialmente favoráveis para a utilização dessa chaminé solar.
\end{abstract}

Palavras-chave: Chaminé solar. Ventilação natural. EnergyPlus. Conforto térmico. Renovação de ar.

\section{Abstract}

The use of natural ventilation strategies to provide thermal comfort and air changes is necessary in most of the Brazilian territory. In this context, solar chimneys can promote benefits such as increase air changes and enhance the thermal comfort of building users. This paper aims to investigate the ability of a solar chimney model to provide thermal comfort and air changes in classrooms and offices. We ran two stages of energy performance simulations on EnergyPlus: the first stage evaluated parameters such as height, number of installed devices per room and solar orientation aimed at providing more hours of comfort and air renewal in four Brazilian cities; the second stage expanded the scope of the devices/rooms simulated to eight Brazilian cities. In the second evaluation, the variation of climate conditions had an impact of up to $80 \%$ on comfort hours. The influence of the devices led to an average increase of $28 \%$ in comfort in classrooms and $21 \%$ in offices. The air change rates were between 2.4 and $13.5 \mathrm{ACH}$. The best performances were observed in the cities in $Z B 1, Z B 2, Z B 3, Z B 4$, and $Z B 5$, demonstrating the potential benefits using this solar chimney in those bioclimatic zones.

Recebido em 26/08/19 Aceito em 06/12/19
Keywords: Solar chimney. Natural ventilation. EnergyPlus. Thermal confort. Air changes. 


\section{Introdução}

As condições térmicas dos ambientes internos afetam o conforto e também influenciam na termorregulação fisiológica e nos processos psicológicos. Tais fatores podem influenciar a produtividade e o desempenho geral do usuário em determinadas tarefas (DE DEAR et al., 2013, 2015). Logo, proporcionar condições de conforto em ambientes como salas de aula e escritórios é de essencial importância, pois pode aumentar o aprendizado e a produtividade dos usuários (PEREZ; CAPELUTO, 2009; PEREZ, RODRIGUEZ; LOPEZ, 2017; STRAUB et al., 2017).

O conforto térmico é definido pela norma ASHRAE 55 (AMERICAN..., 2013) como uma condição mental do ser humano que expressa a satisfação com as condições térmicas ambientais. A avaliação do nível de conforto é determinada por uma combinação de variáveis, como o tipo de atividade que o usuário realiza e sua vestimenta, a temperatura do ar ambiente e das superfícies circundantes, a velocidade e a umidade relativa do ar (DE DEAR et al., 2013). Logo, a norma é adequada para a utilização em pesquisas que exploram ambientes naturalmente ventilados, como discutido por Cândido et al. (2010a, 2010b) e Cândido, De Dear e Lamberts (2011), que reforçam a necessidade da ventilação natural para proporcionar conforto térmico, principalmente em climas tropicais.

\section{Chaminés solares}

As chaminés solares são dispositivos passivos que proporcionam aumento da ventilação natural nos ambientes em que estão instaladas, o que têm despertado o interesse de projetistas devido à sua longa vida útil e economia para edificações (SHI et al., 2016).

Zhai, Song e Wang (2011), Asadi et al. (2016) e Hosien e Selim (2017) definem as chaminés solares como um sistema de termossifão solar que melhora a qualidade interna do ar ao aumentar as taxas de ventilação natural de ambientes por meio do efeito chaminé. Esses dispositivos possuem como princípio a captação da radiação solar a partir de uma superfície externa envidraçada, voltada para a orientação solar que permita maior incidência de radiação. Essa radiação é transmitida pelo vidro e absorvida pela superfície oposta que aquece o ar no interior da cavidade por radiação e convecção. As parcelas absorvidas e refletidas variam de acordo com as propriedades do vidro utilizado. Por aumentar as renovações de ar, sem necessariamente depender da ação direta do vento, esses dispositivos são especialmente interessantes para os climas tropicais, quentes, úmidos e sem vento (MATHUR et al., 2006; TAN; WONG, 2014).

Embora a chaminé solar tenha sido apresentada como um dispositivo indutor da ventilação natural, Tan e Wong (2014) e Neves e Silva (2017) defendem que as trocas de ar por esquadrias mantidas abertas excedem os fluxos de uma chaminé solar. Portanto, esses dispositivos são justificáveis em edificações em que não é possível ou desejável a abertura de janelas, como em ambientes externos hostis.

Estudos sobre chaminés solares investigaram sua eficiência e aplicabilidade, seja pelo uso de diferentes ferramentas de simulação, períodos de análise ou geometria e materiais. Maciel (2016) propôs e investigou um dispositivo que mescla as características de uma proteção solar convencional (brise) e uma chaminé solar. O produto foi denominado brise-chaminé-solar (BCS) e seu desempenho para a renovação de ar e redução do ofuscamento em ambientes internos foi comprovado a partir de simulação termoenergética nos programas Ansys CFD e EnergyPlus e de medições em modelo construído em escala 1:1. O dispositivo apresentou potencial de redução da temperatura operativa de salas de aula e taxas de renovação de ar que atendem às recomendações para qualidade do ar interno, especialmente nas situações em que consegue alcançar temperaturas superficiais na cavidade da chaminé solar acima de $45^{\circ} \mathrm{C}$.

Lee e Strand (2009) realizaram um estudo utilizando EnergyPlus para quantificar o desempenho de uma chaminé solar ao comparar sua eficiência em duas simulações, pelos períodos de um dia e um ano. Os autores identificaram uma redução da eficácia do dispositivo em até $49 \%$ na simulação anual se comparada a de um único dia. Assim, eles mostraram a importância da simulação anual para o entendimento real da aplicabilidade das chaminés solares, visto que permite a avaliação de condições mais variadas em relação a uma condição padronizada em um único dia.

Além do intervalo de tempo de avaliação, que pode ampliar a análise com uso de outros condicionantes ambientais ou meteorológicos, outros aspectos que merecem atenção são as características geométricas e de materiais. Khanal e Lei (2011) investigaram o desempenho de chaminés solares com foco nos efeitos de parâmetros como variáveis ambientais, ângulo de inclinação e tamanho das aberturas da chaminé. Os autores 
identificaram uma grande variedade de resultados contraditórios relatados na literatura, o que indica que o desempenho de uma chaminé solar não está totalmente compreendido sob o enfoque da ventilação natural.

Neves e Silva (2017) também avaliaram condições climáticas e parâmetros geométricos, ao investigarem o potencial de chaminés solares por meio de uma análise paramétrica para maximizar o seu desempenho em climas típicos do território brasileiro. Os autores avaliaram variações de parâmetros como a espessura da cavidade, o comprimento da chaminé, a inclinação e o tipo de vidro utilizado no coletor solar e compararam chaminés com e sem coletor solar. Os resultados indicaram a aplicabilidade da chaminé solar para promover a ventilação natural em todas as cidades analisadas, com melhores resultados nas cidades mais frias. Entretanto, segundo Neves e Silva (2017), é necessário avaliar as condicionantes ambientais e ajustar os parâmetros supracitados de forma a otimizar o desempenho da chaminé solar para cada clima.

Embora apresentados estudos que comprovaram a aplicação de chaminés solares para os climas brasileiros, não foram encontrados estudos nacionais que avaliaram chaminés solares durante todas as horas do ano, fator que pode influenciar na aplicabilidade desses dispositivos. A exceção é Oliveira e Carlo (2018), que avaliaram os fluxos de ar em chaminés solares como parâmetros referenciais para simulações anuais. Além disso, não foram encontrados estudos, nacionais ou internacionais, que analisaram a influência de chaminés solares em ambientes internos a partir da abordagem do conforto adaptativo.

Em vista disso, o objetivo deste artigo é avaliar a influência de chaminés solares no conforto térmico e na renovação de ar em cidades brasileiras, a partir da variação dos parâmetros altura, número de dispositivos e orientação solar do dispositivo.

\section{Materiais e método}

O método adotado neste trabalho foi baseado em simulação termoenergética com o EnergyPlus. Foram simulados dois tipos de ambientes de uso em horário comercial, um com elevada carga interna, como sala de aula, e outro com baixa carga interna, como escritório, ambos com o modelo de chaminé solar desenvolvido por Maciel (2016). As duas opções de ambientes com elevava e baixa cargas internas irão gerar condições distintas que impactam na diferença de temperatura na entrada e na saída do duto vertical que, por sua vez, é um dos princípios indutores do efeito chaminé. A simulação foi dividida em duas etapas. Na primeira, simulações indicaram as configurações mais adequadas para ambientes localizados em climas quente e frio, ZB1 e ZB8, segundo a NBR 15220 (ABNT, 2005). Foram avaliados parâmetros como altura, número de dispositivos instalados por ambiente e orientação solar, para proporcionar mais horas em conforto e renovação de ar. Na segunda etapa, os parâmetros mais adequados foram selecionados e aplicados em cidades das demais zonas bioclimáticas brasileiras. Nas duas etapas da simulação, a avaliação da influência da chaminé foi feita com base nos índices de conforto adaptativo da norma ASHRAE 55 (AMERICAN..., 2013) a partir da temperatura operativa e da taxa de renovação de ar.

\section{Definição do modelo de chaminé solar}

O modelo de chaminé solar utilizado foi o BCS, que mescla as características de uma proteção solar (brise) e de uma chaminé solar. O dispositivo foi resultado da dissertação de Maciel (2016), que comprovou seu potencial para renovação de ar e redução do ofuscamento por meio de simulação termoenergética e medições. O protótipo foi instalado no edifício anexo ao Departamento de Arquitetura e Urbanismo, localizado na Universidade Federal de Viçosa, em Viçosa, Minas Gerais (Figuras 1 e 2). Para o desenvolvimento do BCS, Maciel (2016) utilizou um único protótipo, instalado simultaneamente em dois ambientes. A autora desenvolveu equações a partir de regressão linear que relacionam a temperatura superficial da placa absorvedora e o fluxo de ar na tampa superior do dispositivo (Figuras 3 e 4). As equações foram comparadas a resultados de simulação termoenergética no EnergyPlus, que simularam as condições de contorno e geometria do protótipo testado pela autora. Os resultados foram apresentados, discutidos e considerados válidos por Oliveira e Carlo (2018), fator que possibilitou novas simulações em diferentes ambientes, parâmetros, zonas bioclimáticas e condições de contorno.

O BCS possui uma geometria retangular com dimensões internas de $0,90 \mathrm{~m}$ por $0,20 \mathrm{~m}, 8,00 \mathrm{~m}$ de altura total, e a conexão entre o dispositivo e o ambiente possui $0,40 \mathrm{~m}$ por 0,85 m, de acordo com as Figuras 3 e 4 .

O BCS é composto por três camadas principais: uma superfície envidraçada; uma cavidade por onde o ar flui; e uma placa absorvedora (Figuras 3 e 4). A placa absorvedora, apresentada na Figura 3a, é composta por duas chapas de aço, uma na cor preta voltada para o interior da cavidade, cuja alta absortância tem como objetivo reemitir a radiação solar absorvida e aquecer o ar na cavidade do dispositivo, e outra de 
fechamento. As chapas são separadas por uma camada de ar para isolamento. A face externa da chapa de fechamento é voltada para a abertura do ambiente interno (Figura 4b) e tem baixa absortância para refletir a radiação visível. Ela também reduz a absorção da radiação térmica pela janela, que é emitida pela placa absorvedora (MACIEL, 2016).

\section{Figura 1 - Brise-chaminé-solar: vista geral}

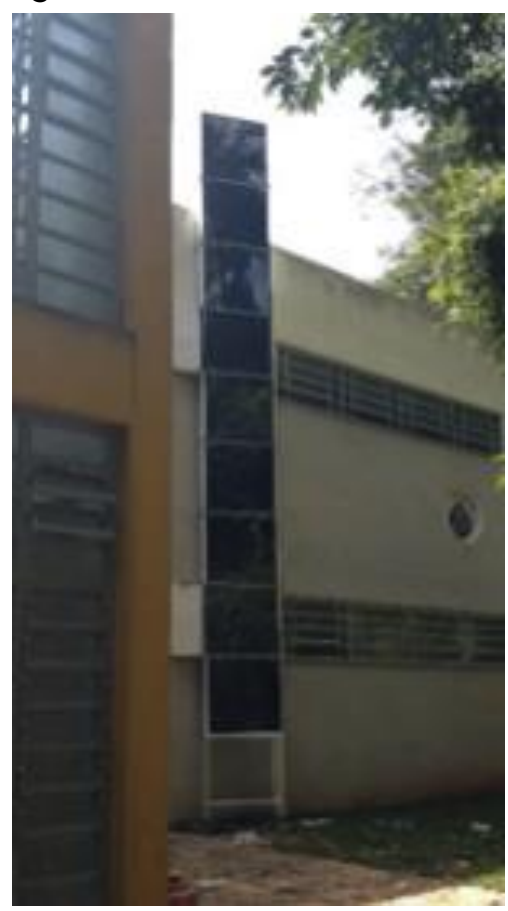

Figura 2 - Brise-chaminé-solar: superfície refletora (direita)

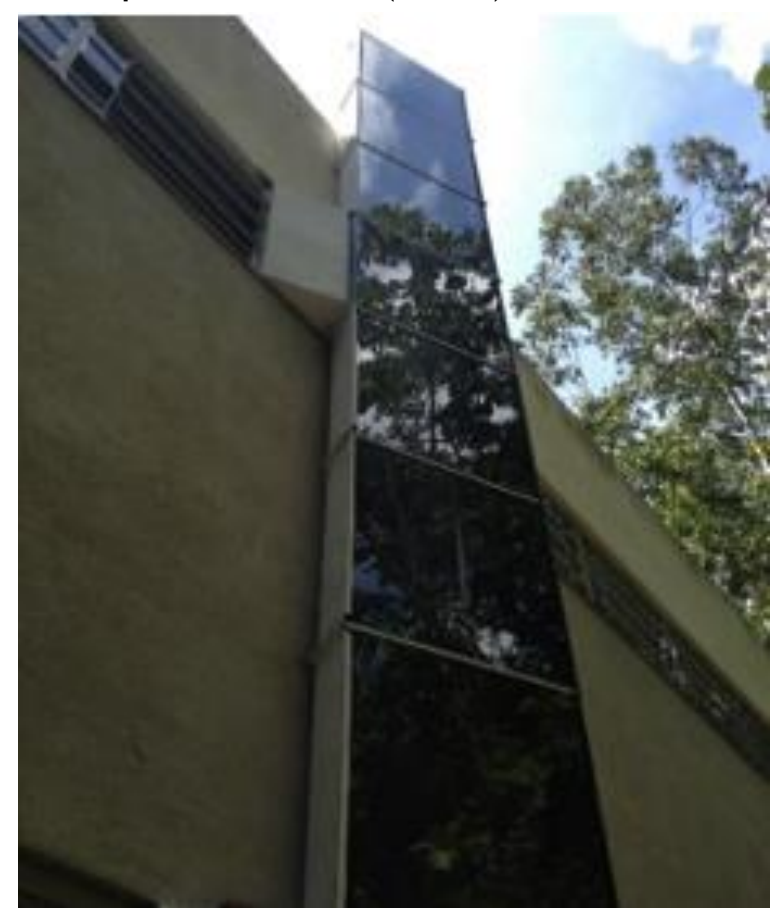

296 Oliveira, M. M.; Carlo, J. C. 
Figura 3 - Seção horizontal do brise-chaminé-solar - (a) dimensões e inclinação com a parede; e (b) conexão entre o brise-chaminé-solar e o ambiente interno

(a)

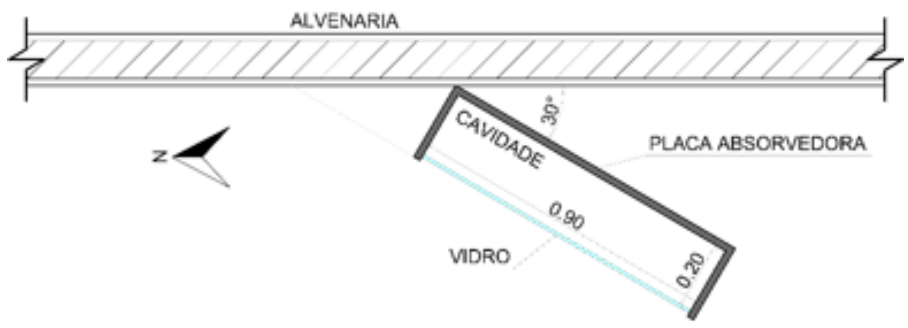

(b)

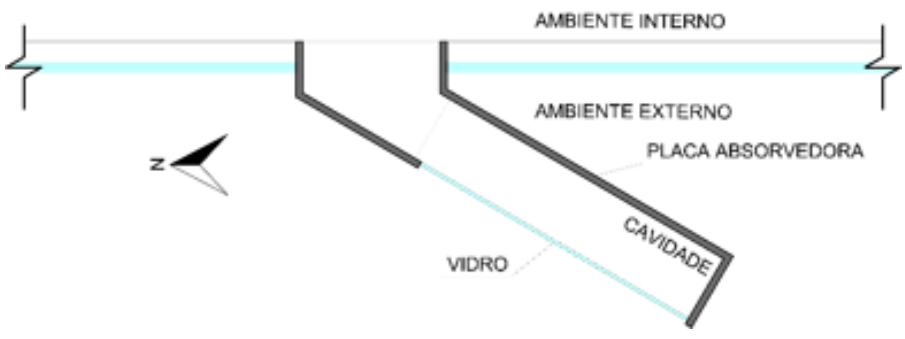

Fonte: adaptado de Maciel (2016).

Figura 4 - Perspectiva isométrica do brise-chaminé-solar

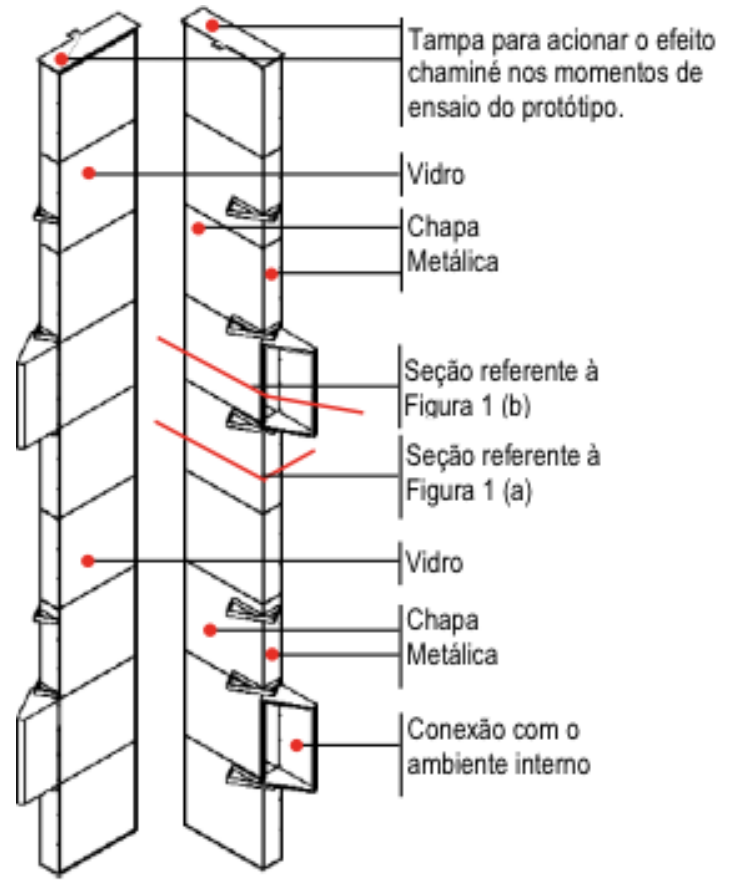

$\begin{array}{ll}\text { (a) Frente } & \text { (b) Fundos }\end{array}$

\section{Definição do ambiente de análise}

As questões relacionadas a saúde, bem-estar e conforto precisam ser abordadas em edificações destinadas à sala de aula, pois os alunos passam em média um terço do dia na escola (ABREU-HARBICH; CHAVES; BRANDSTETTER, 2018). De forma semelhante, pessoas em escritórios despendem parte considerável das horas do dia em atividades que são afetadas pelo nível de conforto térmico do ambiente (DE DEAR et al., 2013, 2015). Logo, as condições de conforto nos ambientes podem melhorar de maneira significativa a eficiência energética dos edifícios e, em ambientes escolares e de escritórios, aumentar a produtividade dos usuários (STRAUB et al., 2017).

A geometria e os usos dos ambientes simulados basearam-se em um levantamento dos artigos do Encontro Nacional de Tecnologia do Ambiente Construído (ENTAC) e Encontro Nacional de Conforto no Ambiente 
Construído (ENCAC) do período 2007-2017. Os artigos foram selecionados por conterem informações relativas às características construtivas de salas de aula e escritórios, adotados como exemplo de ambientes com elevada e baixa carga interna, respectivamente. As informações levantadas foram comprimento, largura, pé-direito e área envidraçada, provenientes de levantamentos e estudos de casos desenvolvidos pelos respectivos autores.

Foram selecionadas 102 salas de aula em 36 artigos em 13 estados e no Distrito Federal. A seleção final da geometria foi definida pela frequência de ocorrência e cada parâmetro foi avaliado separadamente, conforme realizado em outros trabalhos que levantaram e discutiram a representatividade de características construtivas reunidas em um ou mais modelos de simulação (CARLO; TOCOLLINI; LAMBERTS, 2005; CARLO; LAMBERTS, 2008) e que subsidiaram o desenvolvimento do PBE Edifica comercial, de serviços e públicos (MINISTÉRIO..., 2010). Após o levantamento, a sala de aula (alta carga térmica) a ser simulada deveria ter entre $45 \mathrm{~m}^{2}$ e $50 \mathrm{~m}^{2}$, pé-direito entre $2,8 \mathrm{~m}$ e 3,0 m e proporção de janela em relação ao piso entre $20 \%$ e $30 \%$.

Ao verificar as características do escritório (baixa carga térmica), em que foram selecionados 23 artigos e levantados 46 ambientes, a maior frequência de ocorrência de área foi entre $20 \mathrm{~m}^{2}-40 \mathrm{~m}^{2}$. No entanto, dois trabalhos destacaram-se pela abrangência da amostra: Coelho e Ghisi (2007), para a cidade de Florianópolis, $\mathrm{SC}$, cuja maior frequência de ocorrência de área de piso de escritórios foi entre $12 \mathrm{~m}^{2}$ e $60 \mathrm{~m}^{2}$, e Nascimento e Barbosa (2009), que identificaram que 70\% dos escritórios de Londrina, PR, possuem até $50 \mathrm{~m}^{2}$.

Logo, a partir do levantamento realizado, foi possível observar que não existe grande variação entre as características geométricas da sala de aula e do escritório, o que levou à adição de dimensões iguais para os dois ambientes.

\section{Definição das cidades analisadas}

Foram selecionadas cidades nas oito zonas bioclimáticas definidas pela NBR 15220 (ABNT, 2005) de acordo com a disponibilidade dos arquivos climáticos, abrangência territorial e características do clima e latitude.

Neves e Silva (2017) identificaram que em cidades das zonas bioclimáticas 1, 2 e 3 existe um maior potencial de uma chaminé solar proporcionar maiores taxas de vazão volumétrica e taxa de renovação horária. Logo, para avaliar melhor esses climas, foram escolhidas duas cidades na ZB1, ZB2 e ZB3. Nas ZB4 a ZB7 foi selecionada uma cidade de cada e, pelo fato de a ZB8 ocupar 57,8\% do território brasileiro e abranger uma grande amplitude de latitudes, foram selecionadas duas cidades nessa zona. A importância da latitude está na posição solar na abóbada celeste, fator primordial para avaliar o desempenho do ambiente com um dispositivo que é também um brise vertical de geometria padronizada para todos os casos. Assim, os efeitos da radiação incidente na janela poderão ser positivos ou negativos, e fazem parte da análise dos conjuntos ambientes/BCS. O critério de latitudes extremas foi usado para selecionar as duas cidades pertencentes à mesma zona bioclimática (Tabela 1).

Tabela 1-- Cidades selecionadas para a simulação

\begin{tabular}{c|l|c|c|c}
\hline $\begin{array}{c}\text { Zona } \\
\text { bioclimática }\end{array}$ & \multicolumn{1}{|c|}{ Cidade } & $\begin{array}{c}\text { Unidade da } \\
\text { Federação }\end{array}$ & Latitude & $\begin{array}{c}\text { Temperatura } \\
\text { média anual }\end{array}$ \\
\hline \multirow{2}{*}{ ZB1 } & Bento Gonçalves & RS & $29^{\circ} 17^{\prime} \mathrm{S}$ & $17,15^{\circ} \mathrm{C}$ \\
& Campos do Jordão & $\mathrm{SP}$ & $22^{\circ} 74^{\prime} \mathrm{S}$ & $15,30^{\circ} \mathrm{C}$ \\
\hline \multirow{2}{*}{ ZB2 } & Santa Maria & $\mathrm{RS}$ & $29^{\circ} 68^{\prime} \mathrm{S}$ & $19,05^{\circ} \mathrm{C}$ \\
& São João del Rei & $\mathrm{MG}$ & $21^{\circ} 13^{\prime} \mathrm{S}$ & $19,35^{\circ} \mathrm{C}$ \\
\hline \multirow{2}{*}{ ZB3 } & Porto Alegre & $\mathrm{RS}$ & $30^{\circ} 03^{\prime} \mathrm{S}$ & $20,00^{\circ} \mathrm{C}$ \\
& Belo Horizonte & $\mathrm{MG}$ & $19^{\circ} 82^{\prime} \mathrm{S}$ & $21,75^{\circ} \mathrm{C}$ \\
\hline ZB4 & Brasília & $\mathrm{DF}$ & $15^{\circ} 77^{\prime} \mathrm{S}$ & $21,10^{\circ} \mathrm{C}$ \\
\hline ZB5 & Niterói & $\mathrm{RJ}$ & $22^{\circ} 88^{\prime} \mathrm{S}$ & $21,95^{\circ} \mathrm{C}$ \\
\hline ZB6 & Campo Grande & $\mathrm{MS}$ & $20^{\circ} 44^{\prime} \mathrm{S}$ & $23,45^{\circ} \mathrm{C}$ \\
\hline ZB7 & Cuiabá & $\mathrm{MT}$ & $15^{\circ} 59^{\prime} \mathrm{S}$ & $26,25^{\circ} \mathrm{C}$ \\
\hline \multirow{2}{*}{ ZB8 } & Rio de Janeiro & $\mathrm{RJ}$ & $22^{\circ} 90^{\prime} \mathrm{S}$ & $23,15^{\circ} \mathrm{C}$ \\
& Belém & $\mathrm{PA}$ & $01^{\circ} 45^{\prime} \mathrm{S}$ & $27,15^{\circ} \mathrm{C}$ \\
\hline
\end{tabular}




\section{Simulação dos ambientes}

A simulação dos ambientes representativos com o BCS foi realizada com o EnergyPlus 8.4. O ambiente simulado, destacado em vermelho na Figura 5, possui geometria de 7,05 m x 7,05 m, 49,7 $\mathrm{m}^{2}$ de área de piso, pé-direito de $2,90 \mathrm{~m}$ e janelas com área de $10,3 \mathrm{~m}^{2}$ sem contato com o solo ou com a cobertura, cercado por zonas adjacentes de mesmas dimensões (Figuras 5 e 6). As propriedades térmicas dos materiais e parâmetros de uso adotados na simulação do ambiente são apresentadas no Tabela 2, conforme estabelecidos por Maciel (2016) e levantamento apresentado na Definição do ambiente de análise.

O número de dispositivos instalados por ambiente foi determinado com objetivo de proporcionar sombreamento nas aberturas, uma vez que uma das premissas do BCS é funcionar também como um brise. Foram analisados dois cenários, 4 BCS e 8 BCS instalados por ambiente. No primeiro aceita-se a entrada parcial de radiação solar, no segundo a entrada de radiação é mais restritiva (Figura 5).

$\mathrm{Na}$ simulação da sala de aula, de acordo com o levantamento realizado, foram inseridas 41 pessoas (40 alunos e um professor) com metabolismo equivalente a uma pessoa sentada, definido pela norma ASHRAE 55 (AMERICAN..., 2013), um computador e um projetor. Para escritórios foram inseridas seis pessoas em atividade leve de escritório, definido pela norma ASHRAE 55 (AMERICAN..., 2013) e seis computadores (Tabela 2). Nos dois ambientes simulados, as potências de iluminação seguiram a recomendação do manual do RTQ-C (MINISTÉRIO..., 2010), para escola/universidade e escritórios com nível de eficiência A. O ambiente foi simulado para as orientações norte, leste e oeste, por estas apresentarem a maior quantidade de radiação distribuída ao longo do ano.

Figura 5 - Modelo simulado, destaque em vermelho para o ambiente analisado (a) 4 BCS/ambiente; e (b) 8 BCS/ambiente

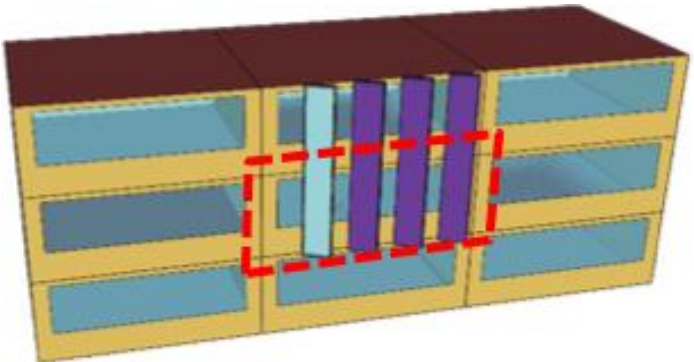

(a)

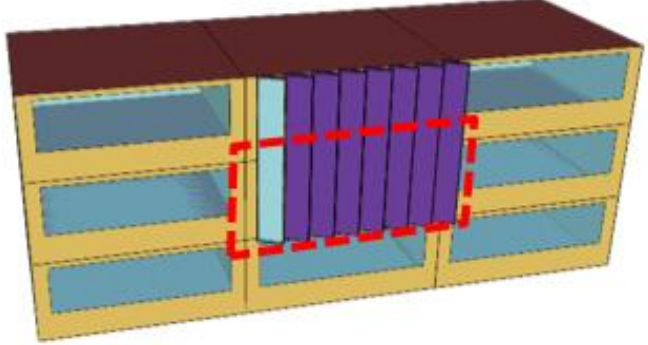

(b)

Figura 6 - Planta do ambiente analisado com 4 BCS

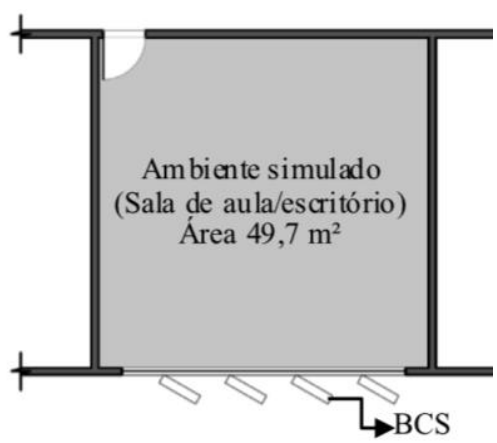

Tabela 2 - Parâmetros adotados na simulação

\begin{tabular}{l|c|c}
\hline \multicolumn{1}{c|}{ Parâmetros da simulação } & Alta carga térmica & Baixa carga térmica \\
\hline Horário de ocupação $(\mathrm{h})$ & $8 \mathrm{~h}-18 \mathrm{~h}$ & $8 \mathrm{~h}-18 \mathrm{~h}$ \\
Densidade de carga interna $\left(\mathrm{W} / \mathrm{m}^{2}\right)$ & 103,0 & 59,6 \\
Transmitância térmica das paredes $\left(\mathrm{W} / \mathrm{m}^{2} \mathrm{~K}\right)$ & 2,5 & 2,5 \\
Capacidade térmica das paredes $\left(\mathrm{kJ} / \mathrm{m}^{2} \mathrm{~K}\right)$ & 150 & 150 \\
Percentual de abertura em relação à fachada $(\%)$ & 50,3 & 50,3 \\
Fator solar de vidro transparente e $=4 \mathrm{~mm}$ & 0,8 & 0,8 \\
\hline
\end{tabular}




\section{Limitações e simplificações da simulação}

Devido à limitação do programa, que simula apenas uma chaminé solar por ambiente, o fluxo de uma chaminé simulada (em ciano na Figura 5) foi multiplicado por quatro, enquanto as demais chaminés foram modeladas apenas como proteções solares (em roxo, Figura 5). Sabe-se que o fluxo de ar de uma chaminé solar não tem uma relação linear com o fluxo de ar de quatro chaminés, mas dois aspectos foram considerados para essa tomada de decisão. Primeiramente, uma chaminé com dimensões maiores teria alteradas as características geométricas a que o fluxo estaria submetido (OLIVEIRA; CARLO, 2018; NEVES; SILVA, 2017). O outro aspecto refere-se à simplificação da modelagem dada à pequena sensibilidade da temperatura operativa à variação do fluxo de ar no EnergyPlus, observada após uma simulação teste. Nela, o fluxo de um BCS foi multiplicado por quatro e inserido como um exaustor integrado ao modelo de ventilação natural em rede do programa. As diferenças de temperatura operativa horária foram, em $99,74 \%$ das horas do ano, menores que $0,5{ }^{\circ} \mathrm{C}$, e em apenas $0,26 \%$ das horas no ano apresentaram diferenças entre $0,5^{\circ} \mathrm{C}$ e $1{ }^{\circ} \mathrm{C}$, o que mostra que a temperatura operativa é pouco sensível à variação dos fluxos de ar proporcionados por quadruplicar a ventilação por chaminés solares.

Outra simplificação foi decorrente do EnergyPlus não simular o efeito chaminé integrado ao modelo de rede de ventilação. Ora, as janelas fechadas geram uma infiltração que deve ocorrer concomitantemente ao efeito chaminé. Assim, o ambiente foi simulado inicialmente com as janelas fechadas e o modelo de rede ativado, para obter a infiltração de ar calculada pelo EnergyPlus e sem a chaminé solar. Essa simulação forneceu a infiltração horária para o ano completo, que foi inserida como um arquivo de entrada de infiltração em uma nova simulação com modelo de rede desativado e a chaminé térmica ativada. Para simplificar o número de entradas nas simulações, foi criado um arquivo com variações horárias de infiltração para cada cidade a partir da média das infiltrações das três orientações avaliadas, norte, leste e oeste. Os métodos e recomendações para a simulação de chaminés solares no EnergyPlus foram baseados no trabalho de Oliveira e Carlo (2018).

\section{Primeira etapa da simulação}

As simulações foram divididas em duas etapas, na primeira foram simulados os ambientes de elevada e baixa carga interna apenas para as cidades da ZB1 e ZB8. Essa etapa teve como objetivo analisar o conforto e a renovação horária do conjunto ambiente/BCS, em climas predominantemente frios ou quentes, e selecionar os melhores casos para serem replicados na segunda etapa das simulações.

Maciel (2016) destacou que, para maximizar a eficiência do dispositivo quanto à ventilação natural, este deve ser conectado, sempre que possível, a apenas um pavimento. Além disso, Maciel (2016) e Zhai, Song e Wang (2011) recomendam a instalação de mais de um dispositivo por ambiente para aumentar a ventilação natural e a renovação do ar. Ambas as recomendações foram acatadas na simulação.

A variação da altura do BCS foi prevista e avaliada por Maciel (2016). A autora, assim como Lee e Strand (2009) e Neves e Silva (2017), concluiu que o aumento da altura de uma chaminé solar tem influência no aumento da velocidade e taxa de renovação de ar. Portanto, quatro alturas foram definidas $(2,90 \mathrm{~m}, 5,80 \mathrm{~m}$, 8,70 m e 14,5 m) de acordo com as tipologias de edificações de sala de aula e escritórios de Carlo, Tocolini e Lamberts (2005), para verificar a influência em proporcionar conforto e renovação de ar nos ambientes. Além disso, a diferença entra as alturas de sala de aula e os escritórios se deve pelas diferenças entre os gabaritos dessas tipologias, comumente maior em escritórios. A altura do BCS de 8,7 m é comum aos dois ambientes e teve como objetivo avaliar o efeito da diferença de carga térmica interna, apresentada na Tabela 2. Nesse estudo não foram analisadas questões relacionadas à exequibilidade da instalação do número de chaminés solares ou da altura destas. Admite-se a importância de tal investigação, mas o objetivo desse trabalho foi entender a influência do número de dispositivos e sua altura, mesmo que as soluções utilizadas apresentem eventuais limitações na execução.

A Tabela 3 resume os parâmetros avaliados na primeira etapa de simulação.

Para o entendimento da contribuição do BCS no conforto ou desconforto do usuário, os melhores casos foram comparados a um caso-base, composto pelo ambiente sem o BCS, ou seja, sem o efeito chaminé, sem sombreamento, e com infiltração idêntica à utilizada nos casos com o BCS. Após as simulações iniciais, foram selecionados os melhores casos: com maior porcentagem de horas ocupadas em conforto, definido pela norma ASHRAE 55 (AMERICAN..., 2013). 
Tabela 3 - Resumo da primeira etapa de simulação

\begin{tabular}{|c|c|c|c|c|c|c|c|c|c|}
\hline & $\mathbf{Z B}$ & Cidade & \multicolumn{3}{|c|}{ Altura do dispositivo (m) } & \multicolumn{2}{|c|}{ Orientação } & \multicolumn{2}{|c|}{$\mathrm{N}^{0}$ de BCS } \\
\hline \multirow{4}{*}{$\begin{array}{l}\frac{\pi}{\Xi} \\
\text { J } \\
\frac{0}{0} \\
\frac{\pi}{\pi} \\
\tilde{\omega}\end{array}$} & \multirow{2}{*}{ ZB1 } & Bento Gonçalves & 2,90 & 5,80 & 8,70 & & $\mathrm{~L} \quad \mathrm{O}$ & 4 & 8 \\
\hline & & Campos do Jordão & 2,90 & 5,80 & 8,70 & $\mathrm{~N}$ & $\mathrm{~L}$ & 4 & 8 \\
\hline & \multirow{2}{*}{ ZB8 } & Rio de Janeiro & 2,90 & 5,80 & 8,70 & $\mathrm{~N}$ & $\mathrm{~L}$ & 4 & 8 \\
\hline & & Belém & 2,90 & 5,80 & 8,70 & & $\mathrm{~L}$ & 4 & 8 \\
\hline \multirow{4}{*}{ 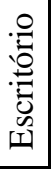 } & \multirow{2}{*}{ ZB1 } & Bento Gonçalves & 8,70 & & 14,50 & & $\mathrm{~L}$ & 4 & 8 \\
\hline & & Campos do Jordão & 8,70 & & 14,50 & $\mathrm{~N}$ & $\mathrm{~L} \quad \mathrm{O}$ & 4 & 8 \\
\hline & \multirow{2}{*}{ ZB8 } & Rio de Janeiro & 8,70 & & 14,50 & & $\mathrm{~L} \quad \mathrm{O}$ & 4 & 8 \\
\hline & & Belém & 8,70 & & 14,50 & $\mathrm{~N}$ & $\mathrm{~L}$ & 4 & 8 \\
\hline
\end{tabular}

\section{Segunda etapa da simulação}

A segunda etapa consiste na simulação dos dois ambientes, com elevada e baixa carga interna, seguindo os parâmetros que proporcionaram melhor relação entre conforto e renovação de ar da primeira etapa, para as demais cidades apresentadas na Tabela 1 .

\section{Resultados e discussão}

\section{Primeira etapa da simulação}

\section{Percentual das horas ocupadas em conforto e renovação de ar em salas de aula}

A combinação de parâmetros que apresentou o maior percentual de horas ocupadas em conforto ${ }^{1}$ (POC) nas salas de aula foi: na cidade de Bento Gonçalves, Campos do Jordão e Belém, 8 BCS com altura de 8,70 m e orientados a norte, com POC de $88 \%, 97 \%$ e $41 \%$, respectivamente; na cidade do Rio de Janeiro, o maior POC foi de $68 \%$ e ocorreu para os mesmos parâmetros, porém na orientação oeste (Quadro 1).

A comparação entre esses ambientes e seus respectivos casos-base apresentou um aumento médio de $24 \%$ das horas do ano em conforto (Tabela 4). A partir da comparação, foi possível afirmar que o BCS influenciou no aumento do POC e na redução das horas em desconforto por calor nas cidades analisadas.

O pior caso ocorreu em Belém, com 4 BCS, altura de 2,90 m, instalados a leste, com 16\% das horas do ano em conforto (Quadro 1 e Figura 9). As condições de contorno que levaram às horas em conforto das Figuras 7 e 9 são apresentadas nas Figuras 8 e 10, referentes à taxa de renovação de ar e radiação solar incidente na janela. Embora a média anual da radiação solar incidente em Belém seja menor que em Campos do Jordão, $153 \mathrm{~W} / \mathrm{m}^{2}$ e $181 \mathrm{~W} / \mathrm{m}^{2}$, respectivamente, a elevada renovação de ar (média mensal de 10 a 12 trocas/h na Figura 8) em um local com temperatura média anual de $15,3{ }^{\circ} \mathrm{C}$ de Campos do Jordão promoveu maior conforto térmico em relação a Belém. Tais condições promoveram uma média anual da temperatura operativa interna de $22,1^{\circ} \mathrm{C}$ em Campos do Jordão e $29,8^{\circ} \mathrm{C}$ em Belém.

Maciel (2016), Lee e Strand (2009) e Neves e Silva (2017) indicaram o aumento da altura de uma chaminé solar como estratégia para incrementar a taxa de renovação de ar, o que pode ser observado nos resultados. Quanto ao desempenho do BCS, a variação na sua altura impactou diretamente o conforto. Em média, para altura de 2,90 m, 59\% das horas foram de conforto, para altura de 5,80 m, 66\%, e para altura de $8,70 \mathrm{~m}$, $68 \%$. No Quadro 1, no entanto, percebe-se que o maior ganho de conforto foi entre a altura de 2,90 m e a altura de 5,80 m (7\%) e, após essa altura, a tendência do dispositivo em influenciar o conforto se reduz.

O número de BCS instalados no ambiente também impactou o POC. Houve um aumento médio de $15 \%$ no conforto dos ambientes que possuíam 8 BCS instalados (Quadro 1). Esse aumento é mais sensível nas cidades da ZB8, em média $23 \%$ maior.

De maneira geral, as maiores renovações ocorreram com os BCS na fachada oeste, pela combinação da incidência de radiação nos horários de maiores temperaturas externas. Nas cidades da ZB1, as renovações de ar não foram uniformes, com valores maiores nos meses mais quentes e menores nos meses mais frios, como exemplificado na Figura 8. Neste, as maiores renovações tenderam a ocorrer nos meses do verão, com

${ }^{1} O$ percentual de horas ocupadas em conforto foi definido no RTQ-C para avaliação do nível de eficiência energética de ambientes e edifícios condicionados naturalmente. Ele é a "Razão entre as horas ocupadas com comprovação de conforto e total de horas ocupadas" (MINISTÉRIO..., 2010, p. 10-11) 
exceção para abril e outubro, com 8 BCS e altura de $8,70 \mathrm{~m}$, que promoveram um máximo de 12,2 trocas por hora. Nas cidades da ZB8 as maiores renovações também foram com 8 BCS, altura de 8,70 m, com máximo de 12,4 trocas por hora, porém sua distribuição foi mais uniforme ao longo do ano (Figura 10).

Quadro 1 - Condições de conforto em ambientes de alta carga interna

\begin{tabular}{|c|c|c|c|c|c|c|c|c|c|c|c|c|}
\hline \multirow{16}{*}{ 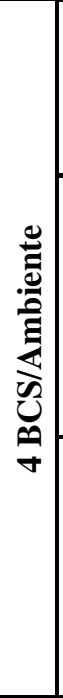 } & \multirow{4}{*}{$\hat{\mathbf{N}}$} & \multirow{4}{*}{ Cidade } & \multirow{4}{*}{$\begin{array}{c}\text { Condição } \\
\text { de } \\
\text { conforto }\end{array}$} & \multicolumn{9}{|c|}{ Altura do brise-chaminé-solar (m) } \\
\hline & & & & 2,90 & $\mathbf{5 , 8 0}$ & 8,70 & 2,90 & $\mathbf{5 , 8 0}$ & 8,70 & 2,90 & $\mathbf{5 , 8 0}$ & 8,70 \\
\hline & & & & \multicolumn{9}{|c|}{ Orientação solar da fachada } \\
\hline & & & & $\mathbf{L}$ & $\mathbf{L}$ & $\mathbf{L}$ & $\mathbf{N}$ & $\mathbf{N}$ & $\mathbf{N}$ & $\mathbf{O}$ & $\mathbf{O}$ & $\mathbf{O}$ \\
\hline & \multirow{6}{*}{$\bar{N}$} & \multirow{3}{*}{$\begin{array}{c}\text { Bento } \\
\text { Gonçalves }\end{array}$} & Frio & $0,9 \%$ & $1,1 \%$ & $1,1 \%$ & $0,6 \%$ & $0,9 \%$ & $1,0 \%$ & $1,1 \%$ & $1,4 \%$ & $1,4 \%$ \\
\hline & & & Conforto & $69,1 \%$ & $75,0 \%$ & $76,3 \%$ & $73,9 \%$ & $80,5 \%$ & $81,9 \%$ & $75,2 \%$ & $80,1 \%$ & $81,2 \%$ \\
\hline & & & Calor & $30,0 \%$ & $24,0 \%$ & $22,6 \%$ & $25,5 \%$ & $18,7 \%$ & $17,1 \%$ & $23,7 \%$ & $18,5 \%$ & $17,3 \%$ \\
\hline & & \multirow{3}{*}{$\begin{array}{c}\text { Campos do } \\
\text { Jordão }\end{array}$} & Frio & $0,1 \%$ & $0,1 \%$ & $0,1 \%$ & $0,1 \%$ & $0,2 \%$ & $0,1 \%$ & $0,1 \%$ & $0,1 \%$ & $0,1 \%$ \\
\hline & & & Conforto & $77,0 \%$ & $84,3 \%$ & $85,9 \%$ & $81,3 \%$ & $96,0 \%$ & $90,9 \%$ & $85,2 \%$ & $90,1 \%$ & $91,3 \%$ \\
\hline & & & Calor & $23,0 \%$ & $15,6 \%$ & $14,0 \%$ & $18,7 \%$ & $3,8 \%$ & $9,1 \%$ & $14,8 \%$ & $9,9 \%$ & $8,6 \%$ \\
\hline & \multirow{6}{*}{$\stackrel{\infty}{\mathbf{N}}$} & \multirow{3}{*}{$\begin{array}{l}\text { Rio de } \\
\text { Janeiro }\end{array}$} & Frio & $0,0 \%$ & $0,0 \%$ & $0,0 \%$ & $0,0 \%$ & $0,0 \%$ & $0,0 \%$ & $0,0 \%$ & $0,0 \%$ & $0,0 \%$ \\
\hline & & & Conforto & $49,5 \%$ & $55,2 \%$ & $56,7 \%$ & & $56,4 \%$ & $57,9 \%$ & $55,5 \%$ & & $62,5 \%$ \\
\hline & & & Calor & $50,5 \%$ & $44,8 \%$ & $43,3 \%$ & $51,7 \%$ & $43,6 \%$ & $42,1 \%$ & $44,5 \%$ & $38,8 \%$ & $37,5 \%$ \\
\hline & & \multirow{3}{*}{ Belém } & Frio & $0,0 \%$ & $0,0 \%$ & $0,0 \%$ & $0,0 \%$ & $0,0 \%$ & $0,0 \%$ & $0,0 \%$ & $0,0 \%$ & $0,0 \%$ \\
\hline & & & & $16,1 \%$ & $21,7 \%$ & $22,9 \%$ & & $30,4 \%$ & $31,5 \%$ & $21,0 \%$ & $26,3 \%$ & $27,3 \%$ \\
\hline & & & Calor & $83,9 \%$ & $78,3 \%$ & $77,1 \%$ & $76,0 \%$ & $69,6 \%$ & $68,5 \%$ & $79,0 \%$ & $73,8 \%$ & $72,7 \%$ \\
\hline \multirow{12}{*}{ 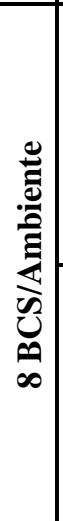 } & \multirow{6}{*}{$\overline{\mathbf{N}}$} & \multirow{3}{*}{$\begin{array}{c}\text { Bento } \\
\text { Gonçalves }\end{array}$} & Frio & $1,0 \%$ & $1,3 \%$ & $1,4 \%$ & $0,8 \%$ & $1,5 \%$ & $1,8 \%$ & $1,2 \%$ & $1,5 \%$ & $1,7 \%$ \\
\hline & & & Conforto & $73,5 \%$ & $82,5 \%$ & $83,6 \%$ & $78,3 \%$ & $86,8 \%$ & $87,7 \%$ & $78,9 \%$ & $84,7 \%$ & $85,9 \%$ \\
\hline & & & Calor & $25,5 \%$ & $16,2 \%$ & $14,9 \%$ & $21,0 \%$ & $11,8 \%$ & $10,5 \%$ & $20,0 \%$ & $13,7 \%$ & $12,4 \%$ \\
\hline & & \multirow{3}{*}{$\begin{array}{l}\text { Campos do } \\
\text { Jordão }\end{array}$} & Frio & $0,1 \%$ & $0,1 \%$ & $0,1 \%$ & $0,1 \%$ & $0,2 \%$ & $0,2 \%$ & $0,1 \%$ & $0,1 \%$ & $0,1 \%$ \\
\hline & & & Conforto & $82,8 \%$ & $91,8 \%$ & $93,5 \%$ & $87,0 \%$ & $96,0 \%$ & $96,6 \%$ & $88,8 \%$ & $94,5 \%$ & $95,5 \%$ \\
\hline & & & Calor & $17,1 \%$ & $8,1 \%$ & $6,4 \%$ & $13,0 \%$ & $3,8 \%$ & $3,2 \%$ & $11,1 \%$ & $5,5 \%$ & $4,4 \%$ \\
\hline & \multirow{6}{*}{$\stackrel{\infty}{\mathbf{N}}$} & \multirow{3}{*}{$\begin{array}{l}\text { Rio de } \\
\text { Janeiro }\end{array}$} & Frio & $0,0 \%$ & $0,0 \%$ & $0,0 \%$ & $0,0 \%$ & $0,0 \%$ & $0,0 \%$ & $0,0 \%$ & $0,0 \%$ & $0,0 \%$ \\
\hline & & & Conforto & $54,2 \%$ & $64,3 \%$ & $65,4 \%$ & $54,3 \%$ & $66,9 \%$ & $68,0 \%$ & $59,3 \%$ & $67,2 \%$ & $68,2 \%$ \\
\hline & & & Calor & $45,9 \%$ & $35,7 \%$ & $34,6 \%$ & $45,7 \%$ & $33,1 \%$ & $32,1 \%$ & $40,7 \%$ & $32,9 \%$ & $31,8 \%$ \\
\hline & & \multirow{3}{*}{ Belém } & Frio & $0,0 \%$ & $0,0 \%$ & $0,0 \%$ & $0,0 \%$ & $0,0 \%$ & $0,0 \%$ & $0,0 \%$ & $0,0 \%$ & $0,0 \%$ \\
\hline & & & Con & $20,7 \%$ & $32,8 \%$ & $34,1 \%$ & $28,5 \%$ & $39,3 \%$ & $40,7 \%$ & $24,6 \%$ & $35,5 \%$ & $36,8 \%$ \\
\hline & & & & $79,3 \%$ & $67,2 \%$ & $65,9 \%$ & $71,5 \%$ & $60,7 \%$ & $59,4 \%$ & $75,4 \%$ & $64,5 \%$ & $63,2 \%$ \\
\hline
\end{tabular}

Nota: Legenda:

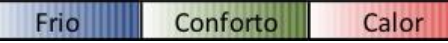

Tabela 4 - Maior diferença entre percentuais de conforto e desconforto entre os casos simulados e o caso-base para salas de aula

\begin{tabular}{c|c|c|c}
\hline Cidade & Conforto & Melhores casos & CB \\
\hline \multirow{3}{*}{ Bento Gonçalves } & Frio & $2 \%$ & $0 \%$ \\
& Conforto & $88 \%$ & $63 \%$ \\
& Calor & $10 \%$ & $36 \%$ \\
\hline \multirow{3}{*}{ Campos do Jordão } & Frio & $0 \%$ & $0 \%$ \\
& Conforto & $97 \%$ & $67 \%$ \\
& Calor & $3 \%$ & $33 \%$ \\
\hline Rio de Janeiro & Frio & $0 \%$ & $0 \%$ \\
& Conforto & $68 \%$ & $49 \%$ \\
& Calor & $32 \%$ & $51 \%$ \\
\hline \multirow{3}{*}{ Belém } & Frio & $0 \%$ & $0 \%$ \\
& Conforto & $41 \%$ & $17 \%$ \\
& Calor & $59 \%$ & $83 \%$ \\
\hline
\end{tabular}


Figura 7 - Distribuição mensal das horas em conforto em salas de aula de Campos do Jordão (8 BCS, 8,70 m e orientação norte)

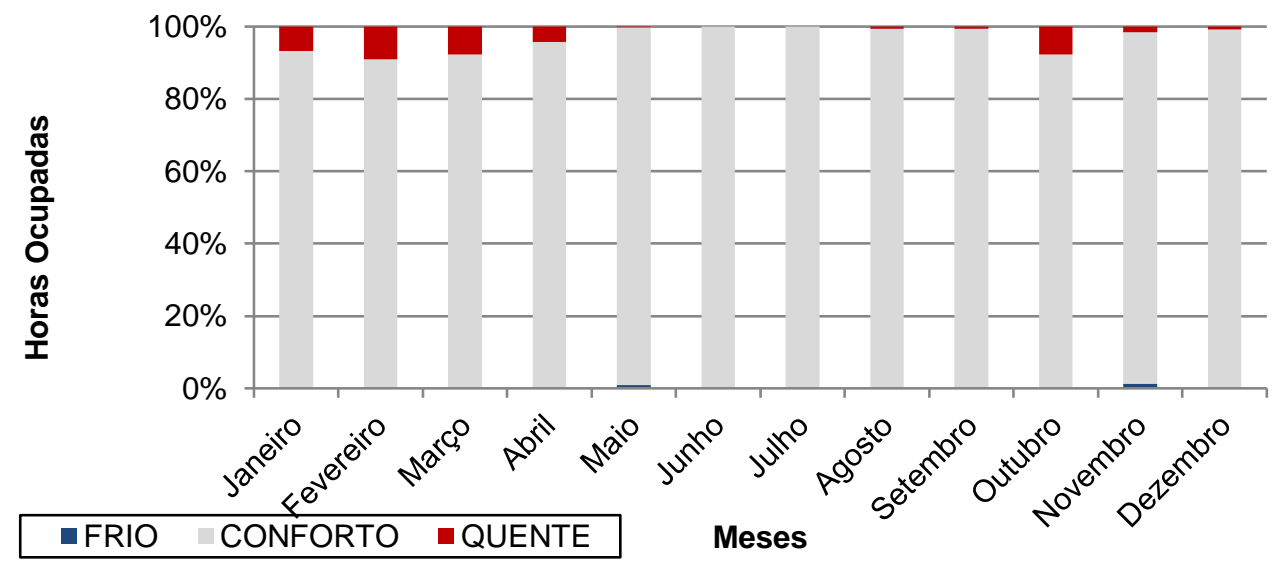

Figura 8 - Médias mensais da renovação de ar horária no ambiente e da radiação solar global horária incidente sobre a janela em salas de aula de Campos do Jordão (8 BCS, 8,70 m e orientação norte)
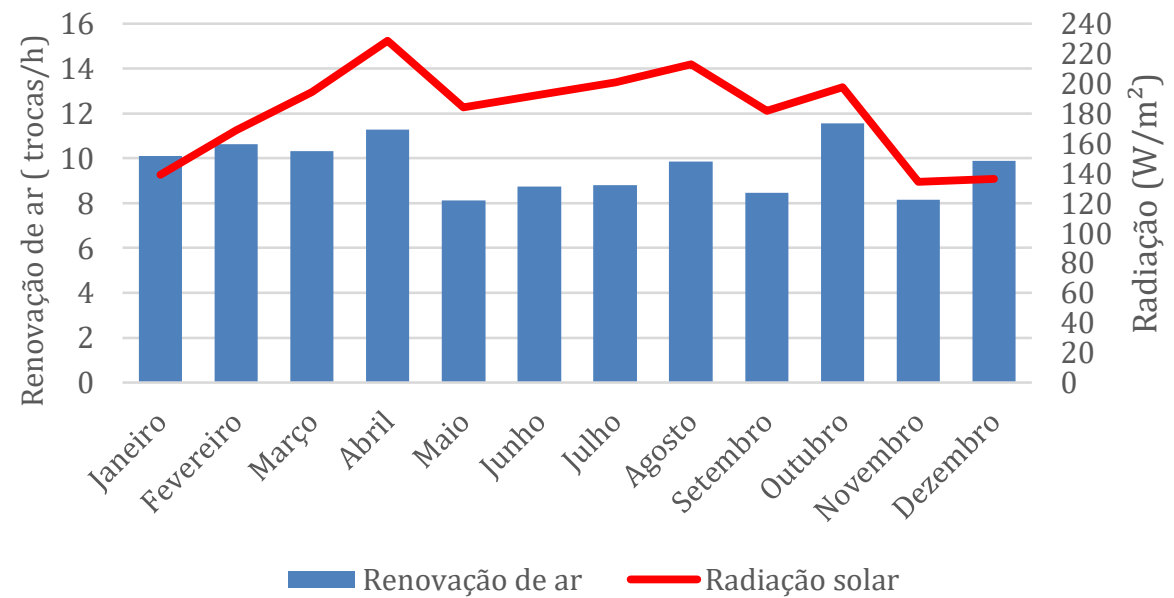

Figura 9 - Distribuição mensal das horas em conforto em salas de aula de Belém (4 BCS, 2,90 m e orientação leste)

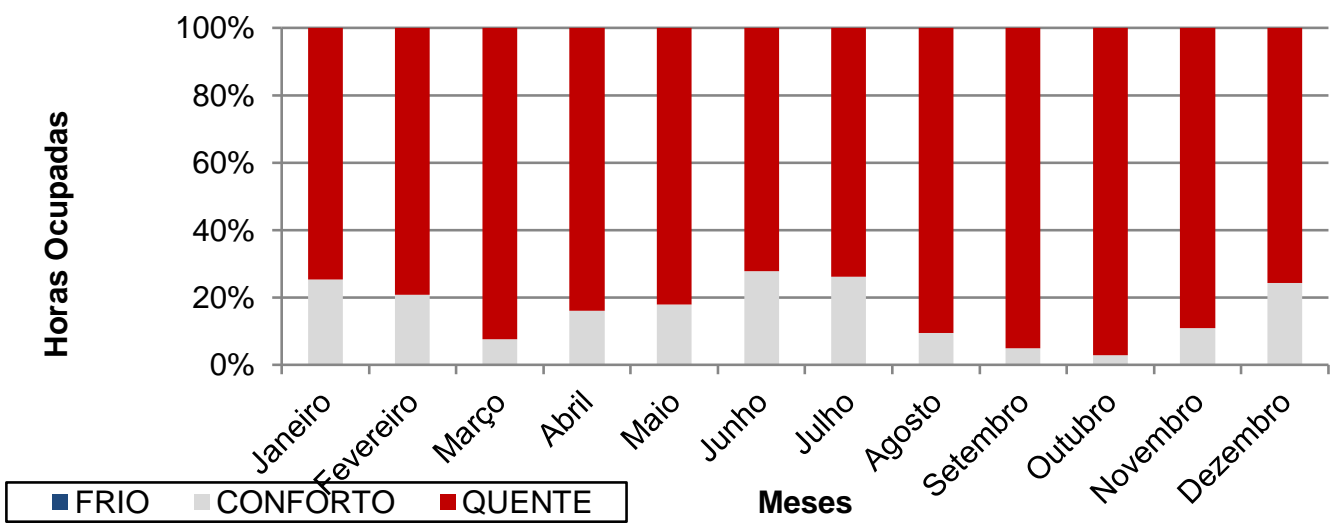


Figura 10 - Médias mensais da renovação de ar horária no ambiente e da radiação solar global horária incidente sobre a janela em salas de aula de Belém (4 BCS, 2,90 m e orientação leste)

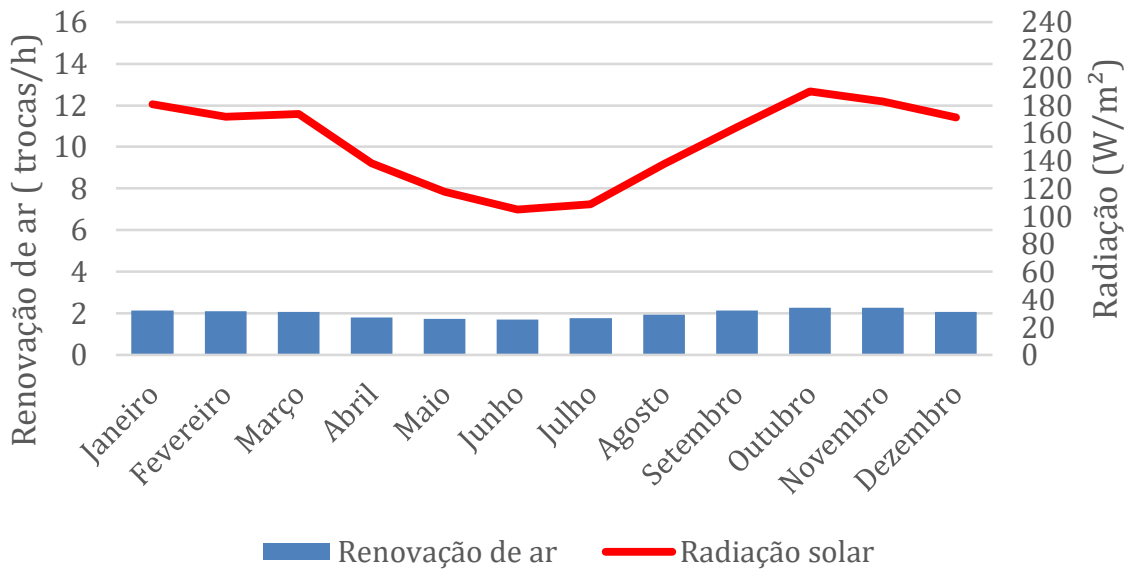

Figura 11 - Média mensal da renovação de ar em salas de aula com 8 BCS em Bento Gonçalves para todas as orientações e alturas

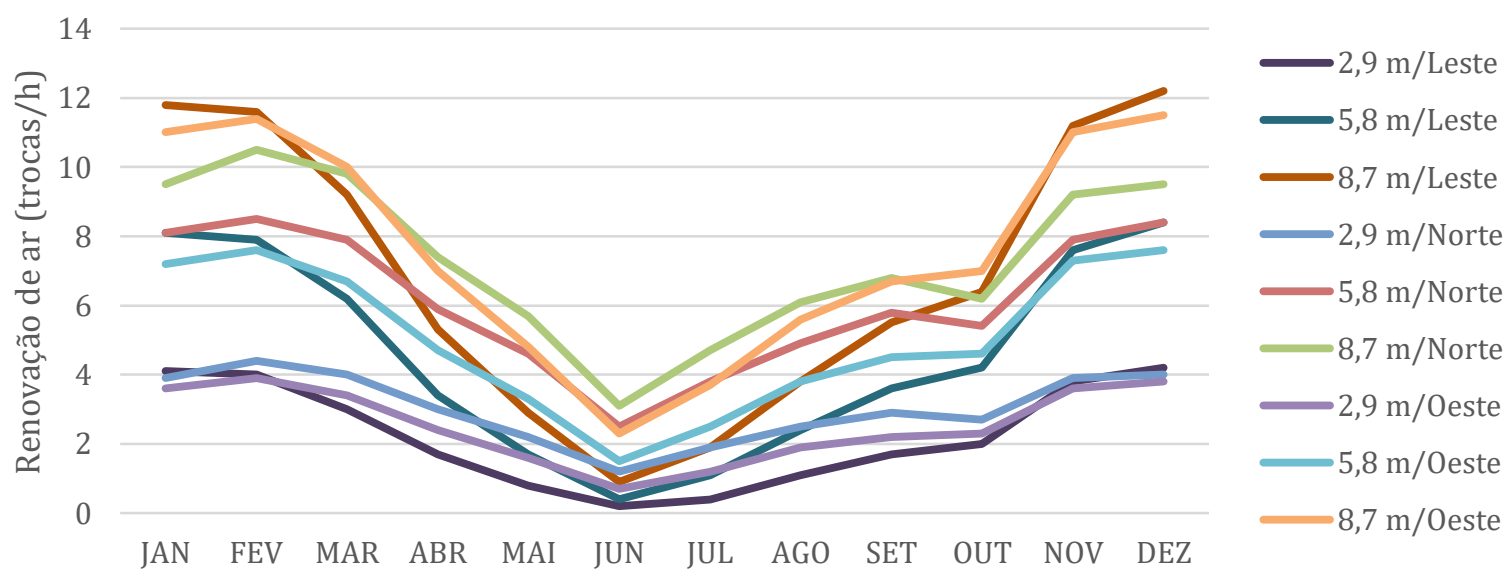

Essa análise completa os resultados obtidos por Neves e Silva (2017), que observaram a intensidade do fluxo de ar em chaminés solares em um momento específico em diferentes cidades brasileiras. Dessa forma, foi possível observar além da intensidade do fluxo de ar para o ano completo, analisar qualitativamente sua sazonalidade.

Foi possível observar que, nas cidades da ZB1, o número de BCS instalados por ambiente impactou de forma mais significativa a taxa de renovação de ar. Para duas vezes mais dispositivos instalados, a média das renovações para a ZB1 foi de 2,3 trocas/hora, com máximo de 5,3 (4 BCS) e 12,2 (8 BCS) contra 2,1 nas cidades da ZB8, com máximo de 6,1 (4 BCS) e 12,4 (8 BCS). A diferença de taxa de renovação resultante da variação do número de BCS instalados (4 BCS para $8 \mathrm{BCS}$ ) nas cidades da ZB1 foi maior no inverno, chegando a 4,9 trocas em julho. Sobre esse aspecto, vê-se a influência da altura solar, cuja radiação incidente sobre o BCS tende a ser mais favorável na superfície vertical no inverno, combinada à diferença de temperatura na cavidade - que está submetida à temperatura externa e principalmente à radiação solar - e no ambiente interno que promovem a ascensão do ar na chaminé (Figura 11). Nas cidades da ZB8 a diferença pelo número de BCS não excedeu 2,3 trocas/h, dada a menor diferença de temperatura entre o exterior e o interior. Também, não foi possível identificar uma tendência pela variação mensal da renovação de ar nas duas cidades da ZB8, que foi acreditada à pequena variação da temperatura externa, como visto na Figura 12 , cuja diferença entre a média no verão e no inverno é de $0,4^{\circ} \mathrm{C}$.

\section{Percentual das horas em conforto e renovação de ar em escritórios}

A combinação de parâmetros que apresentou o maior POC em escritórios foi nas cidades de Bento Gonçalves, Rio de Janeiro e Belém, 8 BCS com altura de 14,5 m e orientados a norte, com POC de $79 \%$, 
$72 \%$ e 46\%, respectivamente; na cidade de Campos do Jordão, as mesmas características, porém para 4 BCS instalados no ambiente, geraram um POC de 90\% (Quadro 2).

Figura 12 - Média mensal da renovação de ar em salas de aula com 8 BCS em Belém para todas as orientações e alturas

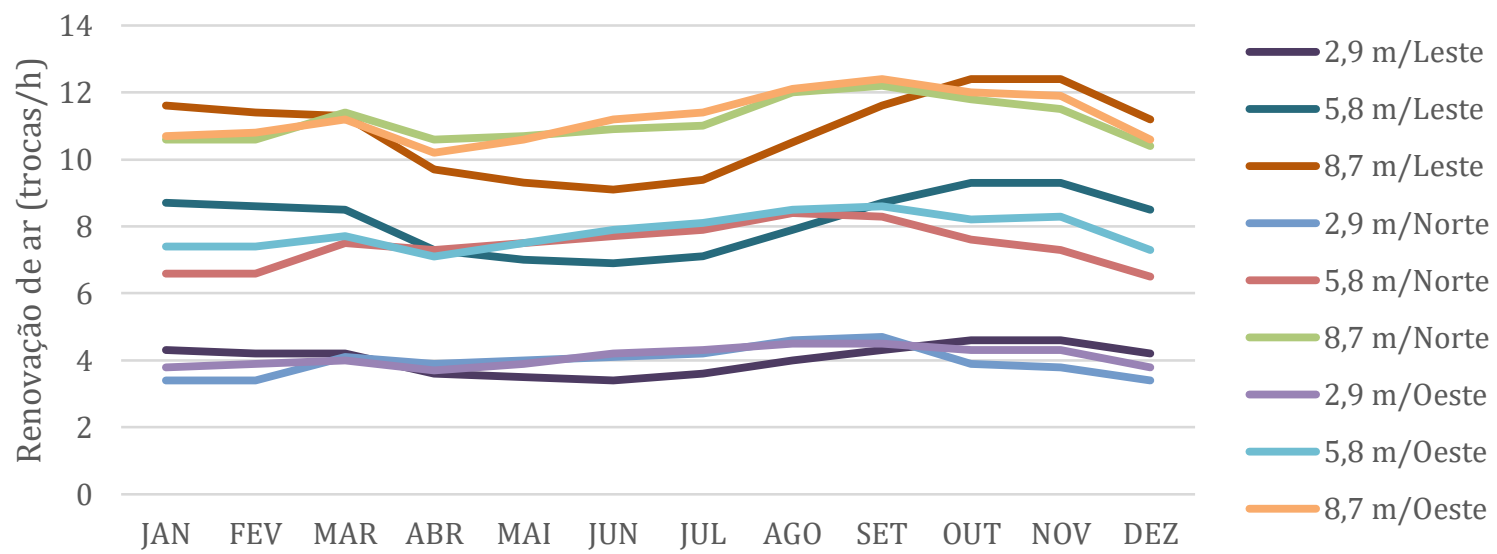

Quadro 2 - Condições de conforto em ambientes com baixa carga interna

\begin{tabular}{|c|c|c|c|c|c|c|c|c|c|}
\hline \multirow{16}{*}{ 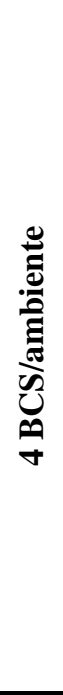 } & \multirow{4}{*}{ जै } & \multirow{4}{*}{ Cidade } & \multirow{4}{*}{$\begin{array}{l}\text { Condição de } \\
\text { conforto }\end{array}$} & \multicolumn{6}{|c|}{ Altura do brise-chaminé-solar } \\
\hline & & & & 8,70 & 14,50 & 8,70 & 14,50 & 8,70 & 14,50 \\
\hline & & & & \multicolumn{6}{|c|}{ Orientação solar da fachada } \\
\hline & & & & $\mathbf{L}$ & $\mathbf{L}$ & $\mathbf{N}$ & $\mathbf{N}$ & $\mathbf{O}$ & $\mathbf{O}$ \\
\hline & \multirow{6}{*}{$\overline{\mathbf{N}}$} & \multirow{3}{*}{ Bento Gonçalves } & \multirow{3}{*}{$\begin{array}{c}\text { Frio } \\
\text { Conforto } \\
\text { Calor }\end{array}$} & $12,0 \%$ & $12,3 \%$ & $10,8 \%$ & $11,7 \%$ & $13,7 \%$ & $14,2 \%$ \\
\hline & & & & $71,4 \%$ & $72,5 \%$ & $77,9 \%$ & $78,2 \%$ & $73,3 \%$ & $74,0 \%$ \\
\hline & & & & $16,6 \%$ & $15,2 \%$ & $11,3 \%$ & $10,1 \%$ & $13,0 \%$ & $11,9 \%$ \\
\hline & & \multirow{3}{*}{ Campos do Jordão } & Frio & $7,2 \%$ & $7,9 \%$ & $6,63 \%$ & $7,3 \%$ & $10,2 \%$ & $11,0 \%$ \\
\hline & & & Conforto & $84,0 \%$ & $85,1 \%$ & $90,0 \%$ & $90,2 \%$ & $84,9 \%$ & $85,1 \%$ \\
\hline & & & Calor & $8,8 \%$ & $7,1 \%$ & $3,39 \%$ & $2,6 \%$ & $5,0 \%$ & $3,9 \%$ \\
\hline & \multirow{6}{*}{$\stackrel{\infty}{N}$} & \multirow{3}{*}{ Rio de Janeiro } & \multirow{3}{*}{$\begin{array}{c}\text { Frio } \\
\text { Conforto } \\
\text { Calor } \\
\end{array}$} & $0,8 \%$ & $0,8 \%$ & $0,6 \%$ & $0,7 \%$ & $0,9 \%$ & $0,9 \%$ \\
\hline & & & & $60,1 \%$ & $61,4 \%$ & $63,0 \%$ & $64,4 \%$ & $65,1 \%$ & $66,2 \%$ \\
\hline & & & & $39,1 \%$ & $37,7 \%$ & $36,3 \%$ & $35,0 \%$ & $34,0 \%$ & $32,9 \%$ \\
\hline & & \multirow{3}{*}{ Belém } & Frio & $0,0 \%$ & $0,0 \%$ & $0,0 \%$ & $0,0 \%$ & $0,0 \%$ & $0,0 \%$ \\
\hline & & & Conforto & $33,5 \%$ & $33,6 \%$ & $39,8 \%$ & $40,6 \%$ & $36,2 \%$ & $36,5 \%$ \\
\hline & & & Calor & $66,6 \%$ & $66,4 \%$ & $60,2 \%$ & $59,4 \%$ & $63,8 \%$ & $63,5 \%$ \\
\hline \multirow{12}{*}{ 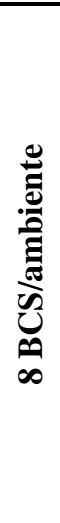 } & \multirow{6}{*}{$\overline{\mathbf{N}}$} & \multirow{3}{*}{ Bento Gonçalves } & \multirow{3}{*}{$\begin{array}{c}\text { Frio } \\
\text { Conforto } \\
\text { Calor } \\
\end{array}$} & $14,0 \%$ & $14,7 \%$ & $14,1 \%$ & $14,7 \%$ & $14,9 \%$ & $15,7 \%$ \\
\hline & & & & $75,3 \%$ & $75,8 \%$ & $78,3 \%$ & $78,8 \%$ & $75,9 \%$ & $76,2 \%$ \\
\hline & & & & $10,8 \%$ & $9,5 \%$ & $7,6 \%$ & $6,5 \%$ & $9,1 \%$ & $8,1 \%$ \\
\hline & & \multirow{3}{*}{ Campos do Jordão } & Frio & $10,5 \%$ & $11,3 \%$ & $10,3 \%$ & $11,5 \%$ & $12,8 \%$ & $13,3 \%$ \\
\hline & & & Conforto & $86,3 \%$ & $86,2 \%$ & $88,6 \%$ & $87,9 \%$ & $85,2 \%$ & $85,1 \%$ \\
\hline & & & Calor & $3,2 \%$ & $2,4 \%$ & $1,10 \%$ & $0,7 \%$ & $2,0 \%$ & $1,6 \%$ \\
\hline & \multirow{6}{*}{$\stackrel{\infty}{N}$} & \multirow{3}{*}{ Rio de Janeiro } & Frio & $1,0 \%$ & $1,0 \%$ & $0,7 \%$ & $0,9 \%$ & $1,0 \%$ & $1,0 \%$ \\
\hline & & & Conforto & $67,2 \%$ & $68,2 \%$ & $70,6 \%$ & $71,6 \%$ & $69,9 \%$ & $70,9 \%$ \\
\hline & & & Calor & $31,9 \%$ & $30,8 \%$ & $28,7 \%$ & $27,5 \%$ & $29,1 \%$ & $28,1 \%$ \\
\hline & & \multirow{3}{*}{ Belém } & \multirow{3}{*}{$\begin{array}{c}\text { Frio } \\
\text { Conforto } \\
\text { Calor }\end{array}$} & $0,0 \%$ & $0,0 \%$ & $0,0 \%$ & $0,0 \%$ & $0,0 \%$ & $0,0 \%$ \\
\hline & & & & $41,4 \%$ & $42,6 \%$ & $44,3 \%$ & $45,7 \%$ & $41,9 \%$ & $43,3 \%$ \\
\hline & & & & $58,6 \%$ & $57,4 \%$ & $55,7 \%$ & $54,3 \%$ & $58,1 \%$ & $56,7 \%$ \\
\hline
\end{tabular}

Nota: Legenda:

\begin{tabular}{l||l||l|} 
Frio & Conforto & Calor \\
\hline
\end{tabular}


A comparação entre esses ambientes e seus respectivos casos-base apresentou um aumento médio de $16 \%$ das horas do ano em conforto (Tabela 5). A partir da comparação foi possível afirmar que o BCS influenciou no aumento das horas em conforto e na redução das horas em desconforto por calor nas cidades analisadas.

O caso que apresentou o maior POC foi o da cidade de Campos do Jordão, 90,2\% com 4 BCS e com altura de 14,5 m, para a orientação norte (Quadro 2 e Figura 13). Mas a radiação solar idêntica à incidente na sala de aula da Figura 8 não promoveu a ascensão do ar com a mesma eficácia, devido à maior carga interna por ocupação na primeira em relação à segunda. Ainda, a renovação de ar mais baixa nos escritórios (Figura 14) que nas salas de aula não evitou o maior desconforto no inverno indicado na Figura 13.

O pior caso ocorreu em Belém, com 4 BCS, altura de 8,70 m e orientação leste, com 33,5\% das horas do ano em conforto (Quadro 2). A renovação de ar aumentou em relação às salas de aula, de um máximo de 2,3 trocas/h para 6,5 trocas/h, que influenciou nas horas de conforto: na sala de aula não chegou a $30 \%$ e no escritório alcançou $47 \%$. A contribuição da carga térmica interna proporcionou uma média anual da temperatura operativa de $29,4{ }^{\circ} \mathrm{C}$ e influenciou, juntamente com a radiação sobre o BCS, no incremento da renovação de ar que, por sua vez, também afetou as horas em conforto.

A variação na altura do BCS nos escritórios impactou menos as horas em conforto, se comparada às salas de aula. Com esses resultados, foi possível observar que a partir da altura de 8,70 m (Quadro 2) a influência do BCS nas horas em conforto tendeu a reduzir.

O número de BCS instalados no ambiente também impactou menos as horas de conforto, 4\%, se comparada aos $15 \%$ das salas de aula (Quadro 2). Por outro lado, as horas em desconforto por frio foram consideravelmente maiores nos escritórios, se comparado às salas de aula, devido à menor densidade de carga térmica interna.

Tabela 4 - Comparação entre os melhores casos simulados e o caso-base/escritório

\begin{tabular}{c|c|c|c}
\hline Cidade & Conforto & Melhores Casos & CB \\
\hline \multirow{3}{*}{ Bento Gonçalves } & Frio & $15 \%$ & $6 \%$ \\
& Conforto & $79 \%$ & $67 \%$ \\
& Calor & $6 \%$ & $26 \%$ \\
\hline \multirow{3}{*}{ Campos do Jordão } & Frio & $7 \%$ & $2 \%$ \\
& Conforto & $90 \%$ & $77 \%$ \\
& Calor & $3 \%$ & $21 \%$ \\
\hline \multirow{2}{*}{ Rio de Janeiro } & Frio & $1 \%$ & $0 \%$ \\
& Conforto & $72 \%$ & $46 \%$ \\
& Calor & $28 \%$ & $53 \%$ \\
\hline \multirow{3}{*}{ Belém } & Frio & $0 \%$ & $0 \%$ \\
& Conforto & $46 \%$ & $32 \%$ \\
& Calor & $54 \%$ & $68 \%$ \\
\hline
\end{tabular}

Figura 13 - Distribuição mensal das horas em conforto na cidade de Campos do Jordão (4 BCS, 14,5 m e orientação norte)

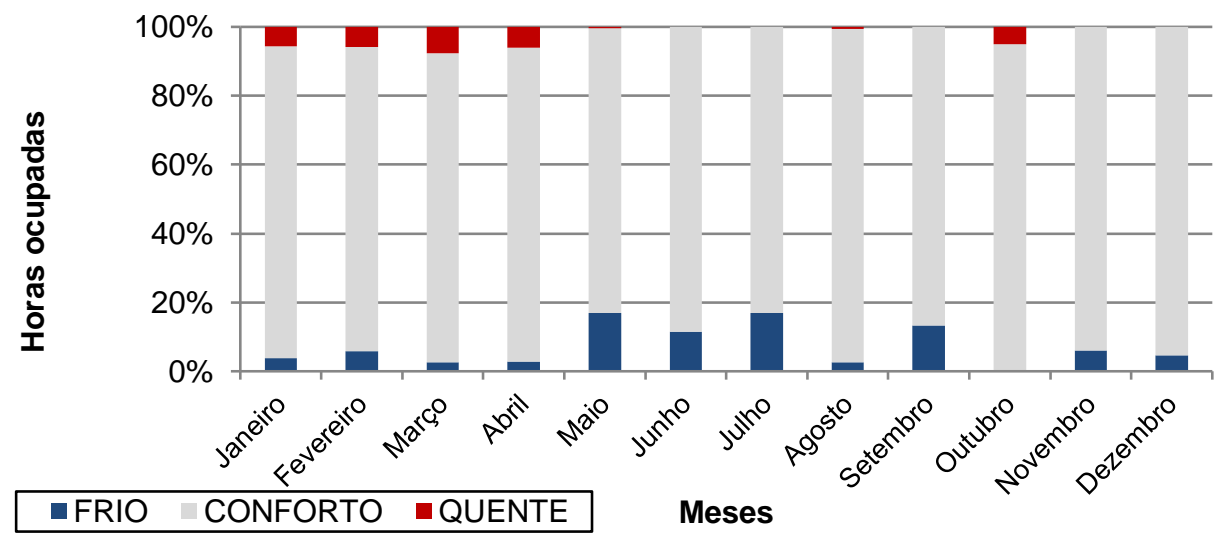

Fonte: elaborado pelos autores. 
Figura 14 - Médias mensais da renovação de ar horária no ambiente e da radiação solar global horária incidente sobre a janela em escritórios de Campos do Jordão (4 BCS, 14,5 m e orientação norte)

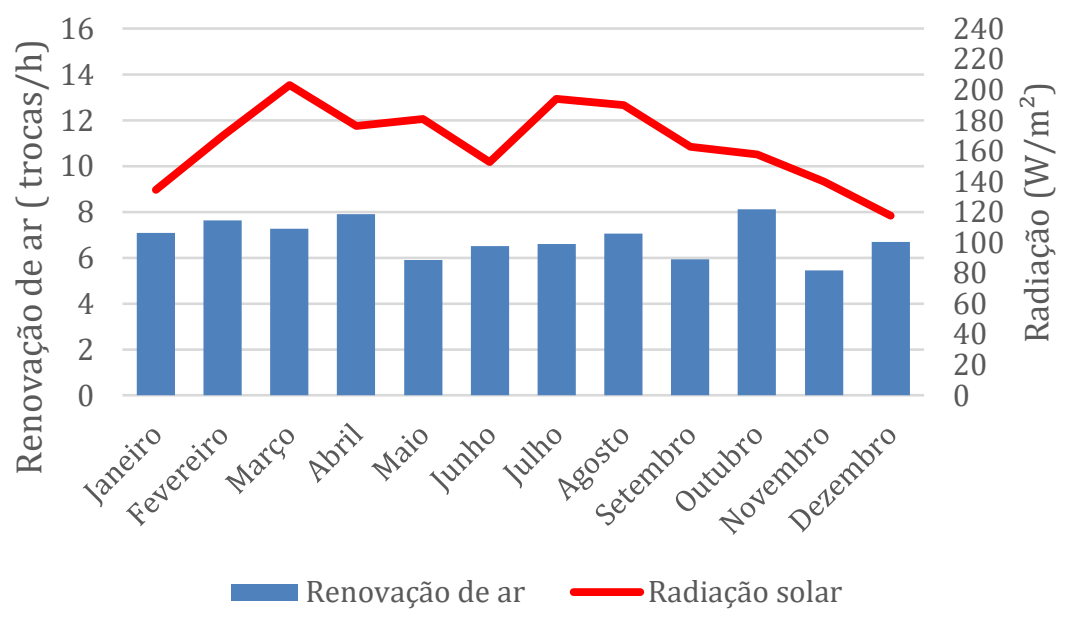

Assim como as salas de aula, as maiores renovações ocorreram na fachada oeste pela combinação da incidência de radiação nos horários de maiores temperaturas externas. Nas cidades da ZB1, as maiores renovações de ar ocorreram nos meses do verão, como nas salas de aula, exemplificado na Figura 14. Nas cidades da ZB8 as maiores trocas foram com 8 BCS e altura de 14,5 m, com máximo de 18,5 trocas por hora e a distribuição uniforme. Se comparada aos demais casos, a renovação de ar obtida para altura de $14,5 \mathrm{~m}$ foi em média $67 \%$ maior que altura de 8,70 m, para todos os climas. De fato, Lee e Strand (2009) apontam que esse fenômeno se deve principalmente pelo fato de o canal de ar mais longo fornecer um caminho mais extenso para a transferência de calor entre a superfície absorvedora e o ar no interior da cavidade, aumentando o efeito chaminé e consequentemente as taxas de renovação de ar.

\section{Correlação entre conforto e renovação de ar}

Dados os resultados anteriores, analisou-se a correlação entre a taxa de renovação de ar promovida pelo BCS e as horas em conforto térmico.

Na primeira etapa de simulação em salas de aula, os resultados apresentaram correlações tanto fracas quanto fortes (coeficiente de determinação mínimo de 0,215 e máximo de 0,949). Para todas os parâmetros analisados, as correlações mais fortes foram nas cidades da ZB1, em que a orientação leste de Bento Gonçalves apresentou as mais fortes correlações (Figura 15). Nas cidades da ZB8 as correlações foram variadas, mas a cidade de Belém apresentou um intervalo maior de coeficientes de determinação, de 0,215 a 0,666, enquanto no Rio de Janeiro foram observados coeficientes de determinação de 0,595 a 0,887.

De maneira geral, os escritórios apresentaram correlações mais fracas que as salas de aula, cujos coeficientes de determinação variaram de 0,001 a 0,784, para todas as cidades analisadas. Se comparada as salas de aula aos escritórios, é possível observar uma inversão nas melhores correlações, em que os escritórios da ZB8, com destaque para o Rio de Janeiro ( $\mathrm{R}^{2}$ mínimo de 0,307 e máximo de 0,784$)$, apresentaram os melhores resultados, se comparados a Campos do Jordão ( $\mathrm{R}^{2}$ mínimo de 0,001 e máximo de 0,686 ).

A partir dos resultados, foi possível identificar que a densidade de carga interna das salas de aula, que é maior devido ao número de ocupantes, mantém uma maior estabilidade da relação POC x renovação de ar.

Outro fator importante é a latitude da cidade e consequentemente a maior ou menor incidência de radiação solar no BCS/ambiente, visto que o escritório no Rio de Janeiro apresentou correlações maiores que Belém.

Foi possível observar uma relação complexa entre as horas em conforto, a densidade de carga interna, a incidência de radiação solar no BCS e a taxa de renovação de ar. Se a cidade pertence à ZB8, portanto é quente, e se recebe mais radiação no BCS, a correlação apresenta resultados médios. Para a mesma cidade, a baixa radiação solar incidente no BCS altera a correlação, que se reduz visto que a renovação do ar é menor e a velocidade do ar influencia menos o conforto. Se a cidade for fria, portanto da ZB1, se o ambiente tem baixa densidade de carga térmica interna e o BCS tem alta incidência de radiação solar, são obtidas as piores correlações entre POC e taxas de renovação de ar, pois a radiação não participa do aquecimento do ambiente por ser absorvida pelo BCS, tampouco a carga interna é suficiente para contribuir para esse aquecimento. 
Assim, outros aspectos ambientais internos influenciam mais o conforto que não a renovação de ar, como a temperatura radiante. Entretanto, a mesma cidade fria, mas com alta densidade de carga térmica interna e alta incidência de radiação solar no BCS, gera condições mais elevadas de correlações entre POC e taxas de renovação de ar (Figura 15), visto que tais condições impactam diretamente a diferença de temperatura de entrada e saída da chaminé que eleva a renovação de ar e, por sua vez, tem grande impacto no conforto, sobrepondo-se a variáveis ambientais como a temperatura radiante das superfícies internas.

\section{Análise dos parâmetros na primeira etapa de simulação}

A partir do cruzamento das informações obtidas na primeira etapa da simulação, os parâmetros mais adequados para proporcionar conforto e renovação de ar foram, em ambientes com alta carga térmica: 8 BCS instalados por ambiente, cada dispositivo com altura de $8,70 \mathrm{~m}$ e orientados para norte; e em ambientes com baixa carga térmica, 8 BCS instalados por ambiente, cada dispositivo com altura de 14,5 m e orientados também para norte.

Nas salas de aula, foi possível observar uma relação entre o POC e a taxa de renovação de ar em todas as zonas bioclimáticas, uma vez que quanto maior a quantidade de dispositivos instalados e quanto maior a altura desses dispositivos maior o POC e a renovação de ar. Nos escritórios, essa relação não foi verdadeira para a ZB1. Devido à baixa densidade de carga térmica interna e ao excesso de sombreamento causado pelo maior número e altura dos dispositivos, houve redução do POC, embora a taxa de renovação tenha respondido de maneira crescente ao aumento em altura. Tais resultados reforçam a importância de avaliar a densidade de carga térmica interna, principalmente nas zonas bioclimáticas mais frias, em que o desconforto por frio pode ser aumentado pelo uso excessivo de dispositivos altos e, consequentemente, pelo aumento da renovação do ar.

Foi possível observar, a partir dos resultados para as várias condições ambientais, diferenças de mais de $80 \%$ no POC para os mesmos ambientes, além de uma grande variação de taxas de renovação de ar. Esses resultados reforçam as conclusões de Lee e Strand (2009), Neves e Silva (2017) e Hosien e Salim (2017) ao destacarem a importância da avaliação das variáveis ambientais para a utilização de chaminés solares. Além disso, esses resultados contribuem para o entendimento dos climas em que existe a maior influência do BCS no conforto térmico e nas taxas de renovação de ar de salas de aula e escritórios.

\section{Figura 15 - Melhor correlação entre taxa de renovação de ar e POC}

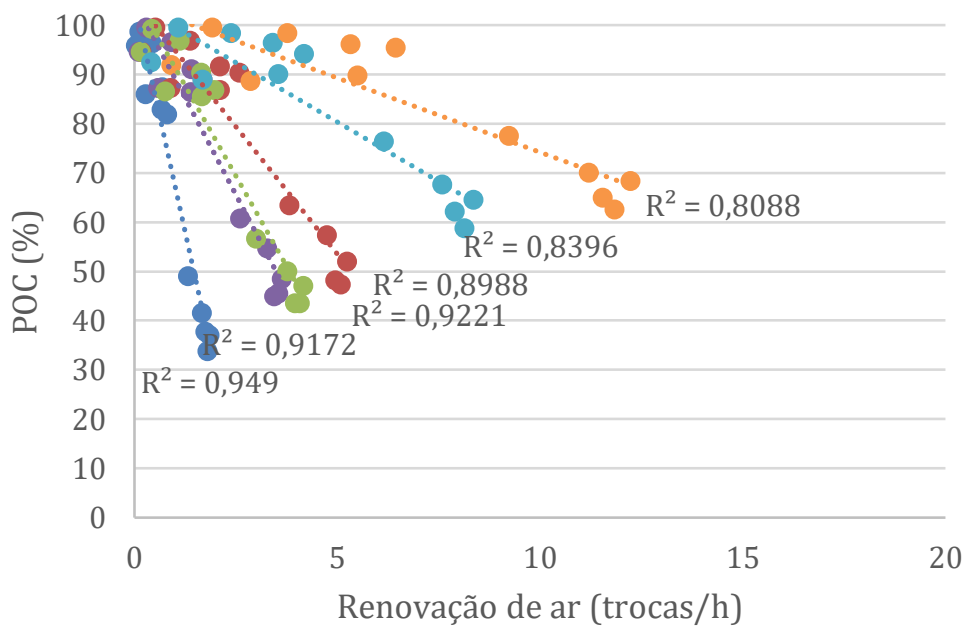

- Bento Gonçalves $(2,9$ $\mathrm{m} /$ leste/4BCS)

- Bento Gonçalves $(5,8$ $\mathrm{m} /$ leste/4BCS)

- Bento Gonçalves $(8,7$ $\mathrm{m} /$ leste/4BCS)

- Bento Gonçalves (2,9 $\mathrm{m} /$ leste/8BCS)

- Bento Gonçalves $(5,8$ $\mathrm{m} /$ leste/8BCS)

- Bento Gonçalves (8,7 $\mathrm{m} /$ leste/8BCS) 


\section{Segunda etapa da simulação: análise do conjunto ambiente/BCS em cidades nas diferentes zonas bioclimáticas}

Embora na simulação das salas de aula na primeira etapa o maior número de horas em conforto tenha sido alcançado com a altura de $8,70 \mathrm{~m}$, para a segunda etapa da simulação, foram utilizados os BCS com altura de $5,80 \mathrm{~m}$. A escolha pela altura de $5,80 \mathrm{~m}$ se justifica devido à diferença entre as horas em conforto ser pequena e a altura de 5,80 m apresentar a melhor relação entre conforto e renovação de ar. Da mesma forma, embora na simulação dos escritórios o maior número de horas em conforto tenha sido alcançado com altura de $14,5 \mathrm{~m}$, para a segunda etapa da simulação foram utilizados os BCS com altura de 8,70 m pelos mesmos motivos.

Portanto, na segunda etapa da simulação para salas de aula, os parâmetros adotados foram 8 BCS instalados por ambiente, cada dispositivo com altura de $5,80 \mathrm{~m}$, orientados para norte. Para escritórios, 8 BCS instalados por ambiente, cada dispositivo com altura de $8,70 \mathrm{~m}$, orientados para norte.

\section{Percentual das horas em conforto}

Como já foi observado, as simulações para as cidades da ZB1 apresentaram o maior POC (Figuras 16 e 17). $\mathrm{Na}$ comparação entre cidades pertencentes à mesma zona bioclimática e com diferentes latitudes, nas ZB1, ZB2 e ZB3 as cidades com menores latitudes apresentaram maior POC para os ambientes com carga térmica alta e baixa. Elas têm em comum a combinação entre temperaturas externas mais próximas ao nível de conforto, maiores taxas de radiação solar incidente no BCS e o sombreamento proporcionado pelo dispositivo. Em contraste, a cidade do Rio de Janeiro (latitude $22^{\circ} 90^{\prime}$ Sul) apresentou uma quantidade de horas em conforto $27 \%$ maior que a cidade de Belém (latitude $01^{\circ} 45^{\prime}$ Sul), devido às diferenças na temperatura externa entre as cidades, maiores em Belém.

Inesperadamente, a simulação dos ambientes com baixa carga térmica nas cidades de Brasília (ZB4) e Niterói (ZB5) apresentaram horas em conforto elevadas, semelhantes aos índices obtidos na ZB2 e ZB3 (Figura 17). Ainda, nas simulações realizadas, os escritórios possuem menor densidade de carga interna se comparados às salas de aula, fator que evitou o aquecimento do ambiente e favoreceu os maiores percentuais de conforto em climas com temperaturas externas intermediárias. Tendo como referência o POC, foi possível agrupar os resultados em três grupos: no primeiro estão as cidades da ZB1 com os maiores valores; no segundo as cidades da ZB2 a ZB5 com POCs intermediários; e o terceiro as cidades da ZB6 a ZB8 com os menores valores de POC (Figuras 16 e 17 e Quadro 3).

A partir da comparação entre os ambientes com o BCS e seus respectivos casos-base, foi possível afirmar que o BCS proporcionou aumento significativo do POC e redução nas horas em desconforto por calor em todas as cidades analisadas (Quadro 3). Nas simulações das salas de aula, Belo Horizonte foi a cidade que apresentou o maior aumento do POC, 45\%, seguida de Brasília, 39\%, Niterói, 35\%, e São João del Rei, $35 \%$. Em escritórios, o maior aumento do POC foi em Brasília, 35\%, seguido de Porto Alegre, 30\%, Niterói, 30\%, e São João del Rei, 27\% (Quadro 3).

Em média, na comparação com o caso-base, o aumento do POC foi de $28 \%$ para ambientes com alta carga térmica e $21 \%$ para ambientes com baixa carga térmica. Em relação às horas em desconforto, o BCS apresentou uma contribuição relevante na redução das horas em desconforto por calor, em média $29 \%$ para salas de aula e $24 \%$ para escritórios. Entretanto, nos escritórios, o BCS causou um aumento médio de 5\% no desconforto por frio nas cidades da ZB1, ZB2 e ZB3, localidades com verão e inverno bem definidos. O aumento do desconforto por frio foi causado pela baixa densidade de carga térmica interna, como comentado anteriormente, associado ao sombreamento causado pelo dispositivo.

Para analisar um caso intermediário, Brasília é uma cidade na ZB4 que apresenta verão e inverno diferenciados, mas não apresentou desconforto por frio no inverno, cujas horas de desconforto por calor e de conforto foram equivalentes a Belo Horizonte da ZB3 e a Niterói na ZB5 (Figuras 16 e 17), esta última sem inverno diferenciado. No caso de Brasília, a média mensal da radiação solar horária que atinge a janela norte das salas de aula e escritórios não tem diferença sazonal, o que mostra que a incidência solar no inverno é sobre a face da chaminé solar. A média mensal de abril a setembro é de 8,4 trocas/hora na sala de aula e 12,1 trocas/hora no escritório, enquanto de outubro a março é de 7,5 trocas/hora na sala de aula e 10,5 trocas/hora no escritório (Figura 18), o que mostra que a variação sazonal do clima local - referente à incidência da radiação solar na fachada norte e da temperatura externa - reflete na taxa de renovação de ar dos ambientes. Assim, no período de frio, em que a ventilação natural por diferença de pressão (vento) é indesejada, a 
renovação de ar por diferença de temperatura (efeito chaminé) é benéfica e, como visto na Tabela 5, pode melhorar as condições de desconforto por calor nesse clima.

Figura 16 - Conforto e desconforto térmico anual para ambientes com alta carga térmica

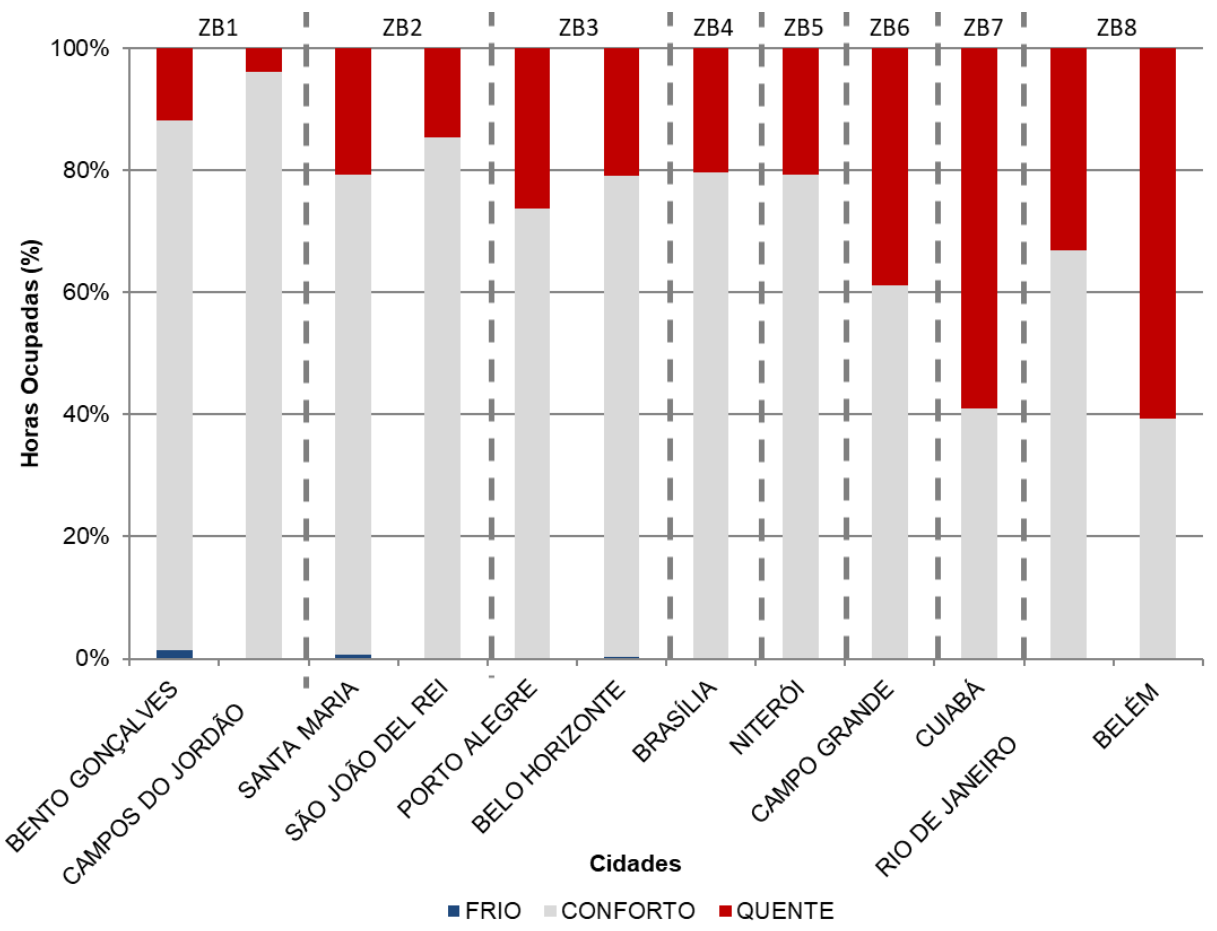

Figura 17 - Conforto e desconforto térmico anual para ambientes com baixa carga térmica

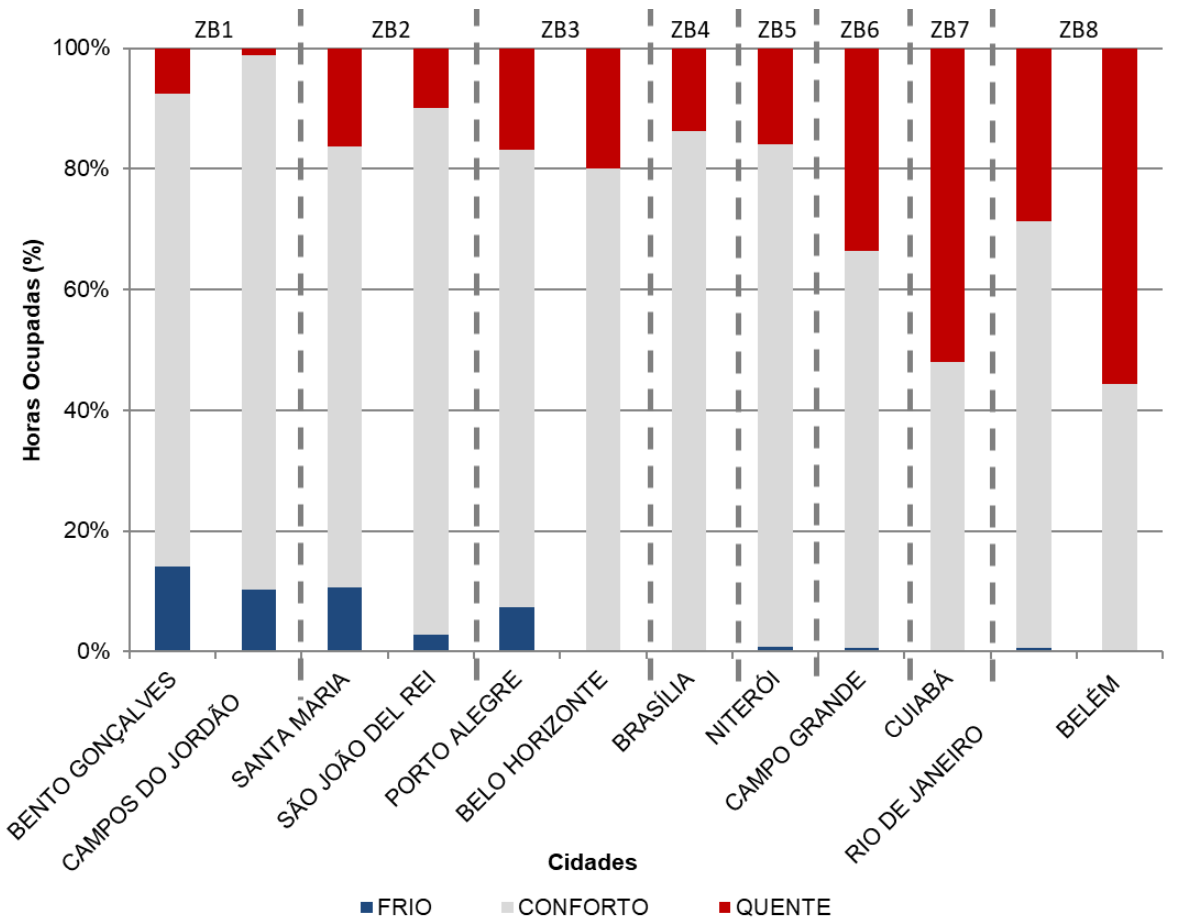


Quadro 3 - Horas em conforto na segunda etapa de simulação

\begin{tabular}{|c|c|c|c|c|c|c|c|c|}
\hline \multirow{2}{*}{$\stackrel{N}{N}$} & \multirow{2}{*}{ Cidade } & \multirow{2}{*}{ Conforto } & \multicolumn{3}{|c|}{ Alta carga térmica } & \multicolumn{3}{|c|}{ Baixa carga térmica } \\
\hline & & & BCS & CB & Diferenca & BCS & CB & Diferenca \\
\hline \multirow{6}{*}{$\bar{N}$} & \multirow{3}{*}{$\begin{array}{c}\text { Bento } \\
\text { Gonçalves }\end{array}$} & Frio & $1 \%$ & $0 \%$ & $1 \%$ & $14 \%$ & $6 \%$ & $8 \%$ \\
\hline & & Conforto & $87 \%$ & $63 \%$ & $24 \%$ & $78 \%$ & $67 \%$ & $11 \%$ \\
\hline & & Calor & $12 \%$ & $36 \%$ & $-24 \%$ & $8 \%$ & $26 \%$ & $-18 \%$ \\
\hline & \multirow{3}{*}{$\begin{array}{l}\text { Campos do } \\
\text { Jordão }\end{array}$} & Frio & $0 \%$ & $0 \%$ & $0 \%$ & $10 \%$ & $2 \%$ & $8 \%$ \\
\hline & & Conforto & $96 \%$ & $67 \%$ & $29 \%$ & $89 \%$ & $77 \%$ & $12 \%$ \\
\hline & & Calor & $4 \%$ & $33 \%$ & $-29 \%$ & $1 \%$ & $21 \%$ & $-20 \%$ \\
\hline \multirow{6}{*}{ ๊ิ } & \multirow{3}{*}{ Santa Maria } & Frio & $1 \%$ & $0 \%$ & $1 \%$ & $11 \%$ & $5 \%$ & $6 \%$ \\
\hline & & Conforto & $79 \%$ & $58 \%$ & $21 \%$ & $73 \%$ & $63 \%$ & $10 \%$ \\
\hline & & Calor & $21 \%$ & $42 \%$ & $-21 \%$ & $16 \%$ & $32 \%$ & $-15 \%$ \\
\hline & \multirow{3}{*}{$\begin{array}{l}\text { São João del } \\
\text { Rei }\end{array}$} & Frio & $0 \%$ & $0 \%$ & $0 \%$ & $3 \%$ & $1 \%$ & $2 \%$ \\
\hline & & Conforto & $85 \%$ & $50 \%$ & $35 \%$ & $87 \%$ & $60 \%$ & $27 \%$ \\
\hline & & Calor & $15 \%$ & $50 \%$ & $-35 \%$ & $10 \%$ & $39 \%$ & $-29 \%$ \\
\hline \multirow{6}{*}{$\tilde{N}$} & \multirow{3}{*}{ Porto Alegre } & Frio & $0 \%$ & $0 \%$ & $0 \%$ & $7 \%$ & $0 \%$ & $7 \%$ \\
\hline & & Conforto & $74 \%$ & $55 \%$ & $19 \%$ & $76 \%$ & $46 \%$ & $30 \%$ \\
\hline & & Calor & $26 \%$ & $45 \%$ & $-19 \%$ & $17 \%$ & $55 \%$ & $-38 \%$ \\
\hline & \multirow{3}{*}{$\begin{array}{l}\text { Belo } \\
\text { Horizonte }\end{array}$} & Frio & $0 \%$ & $0 \%$ & $0 \%$ & $0 \%$ & $3 \%$ & $-3 \%$ \\
\hline & & Conforto & $79 \%$ & $33 \%$ & $45 \%$ & $80 \%$ & $61 \%$ & $19 \%$ \\
\hline & & Calor & $21 \%$ & $67 \%$ & $-46 \%$ & $20 \%$ & $36 \%$ & $-16 \%$ \\
\hline \multirow{3}{*}{$\stackrel{+}{N}$} & \multirow{3}{*}{ Brasília } & Frio & $0 \%$ & $0 \%$ & $0 \%$ & $0 \%$ & $0 \%$ & $0 \%$ \\
\hline & & Conforto & $80 \%$ & $41 \%$ & $39 \%$ & $86 \%$ & $51 \%$ & $35 \%$ \\
\hline & & Calor & $20 \%$ & $59 \%$ & $-39 \%$ & $14 \%$ & $49 \%$ & $-35 \%$ \\
\hline \multirow{3}{*}{$\tilde{N}$} & \multirow{3}{*}{ Niterói } & Frio & $0 \%$ & $0 \%$ & $0 \%$ & $1 \%$ & $0 \%$ & $1 \%$ \\
\hline & & Conforto & $79 \%$ & $44 \%$ & $35 \%$ & $83 \%$ & $54 \%$ & $30 \%$ \\
\hline & & Calor & $21 \%$ & $56 \%$ & $-35 \%$ & $16 \%$ & $46 \%$ & $-30 \%$ \\
\hline \multirow{3}{*}{$\stackrel{\circ}{\stackrel{n}{N}}$} & \multirow{3}{*}{$\begin{array}{l}\text { Campo } \\
\text { Grande }\end{array}$} & Frio & $0 \%$ & $0 \%$ & $0 \%$ & $1 \%$ & $0 \%$ & $1 \%$ \\
\hline & & Conforto & $61 \%$ & $31 \%$ & $31 \%$ & $66 \%$ & $41 \%$ & $25 \%$ \\
\hline & & Calor & $39 \%$ & $69 \%$ & $-31 \%$ & $34 \%$ & $59 \%$ & $-26 \%$ \\
\hline \multirow{3}{*}{$\hat{N}$} & \multirow{3}{*}{ Cuiabá } & Frio & $0 \%$ & $0 \%$ & $0 \%$ & $0 \%$ & $0 \%$ & $0 \%$ \\
\hline & & Conforto & $41 \%$ & $18 \%$ & $23 \%$ & $48 \%$ & $28 \%$ & $20 \%$ \\
\hline & & Calor & $59 \%$ & $82 \%$ & $-23 \%$ & $52 \%$ & $72 \%$ & $-20 \%$ \\
\hline \multirow{6}{*}{$\stackrel{\infty}{N}$} & \multirow{6}{*}{ Rio de Janeiro } & Frio & $0 \%$ & $0 \%$ & $0 \%$ & $1 \%$ & $0 \%$ & $1 \%$ \\
\hline & & Conforto & $67 \%$ & $49 \%$ & $18 \%$ & $71 \%$ & $46 \%$ & $25 \%$ \\
\hline & & Calor & $33 \%$ & $51 \%$ & $-18 \%$ & $29 \%$ & $53 \%$ & $-24 \%$ \\
\hline & & Frio & $0 \%$ & $0 \%$ & $0 \%$ & $0 \%$ & $0 \%$ & $0 \%$ \\
\hline & & Conforto & $39 \%$ & $17 \%$ & $22 \%$ & $44 \%$ & $32 \%$ & $12 \%$ \\
\hline & & Calor & $61 \%$ & $83 \%$ & $-22 \%$ & $56 \%$ & $68 \%$ & $-12 \%$ \\
\hline
\end{tabular}

Figura 18 - Médias mensais da renovação de ar horária no ambiente e da radiação solar global horária incidente sobre a janela em salas de aula e escritórios de Brasília ( $8 \mathrm{BCS}, 8,7 \mathrm{~m}$ e orientação norte)

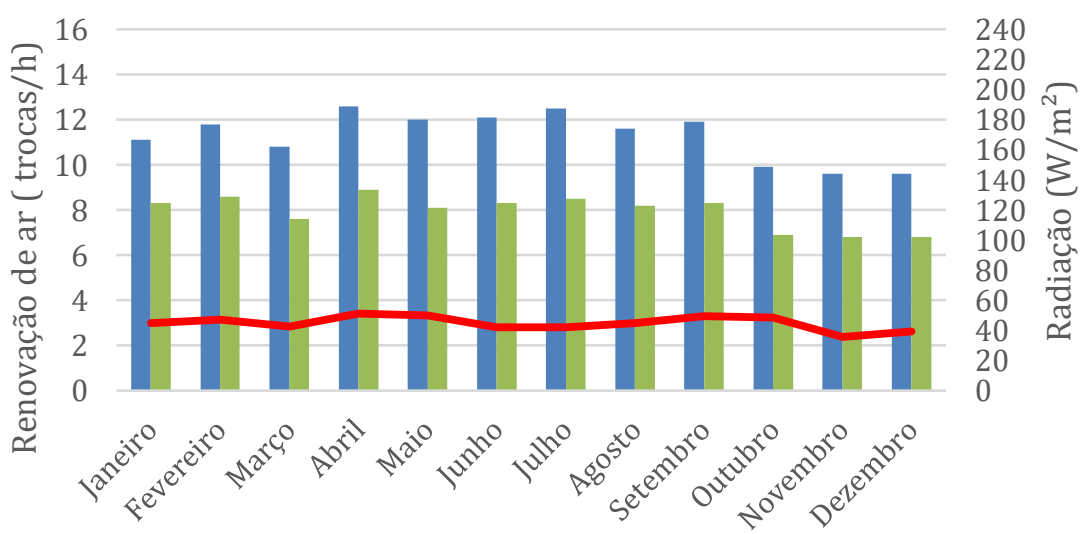

Renovação Escritório $\quad$ Renovação Sala de Aula — Radiação solar 
Sobre os demais resultados de renovação de ar para as localidades analisadas, as maiores taxas foram obtidas nos escritórios, com média mensal de 13,5 trocas/hora em escritórios e 9,9 trocas/hora em salas de aula.

As taxas de renovação de ar na ZB2 e ZB3 seguiram o mesmo padrão apresentado na primeira etapa de simulação para a ZB1, com valores maiores nos meses mais quentes e menores nos meses mais frios, e ainda apresentaram diferenças na ZB4 que são válidas para renovação de ar e conforto. A partir da ZB5 a distribuição da renovação foi mais uniforme e não apresentou diferenças significativas entre os meses do ano.

\section{Conclusão}

O presente artigo teve como objetivo avaliar a influência do BCS em proporcionar conforto térmico e renovação de ar em dois ambientes: salas de aula e escritórios, com densidades de cargas alta e baixa, em diferentes cidades segundo o zoneamento bioclimático brasileiro.

A partir das diferenças entre os climas analisados, foi obtida uma variação de até $80 \%$ no número de horas em conforto, além de uma grande variação de taxas de renovação de ar. Tais resultados reforçam as discussões apresentadas em outras pesquisas, em que a análise do clima em que se pretende instalar uma chaminé solar é fundamental para garantir conforto térmico e as renovações de ar nos ambientes analisados.

Em relação às taxas de renovação de ar, o BCS foi capaz de proporcionar uma média mensal entre 2,4 e 13,5 trocas por hora. É importante destacar que as renovações de ar obtidas através de chaminés solares são menores que as renovações obtidas por janelas mantidas abertas. Portanto, as taxas de renovação obtidas com o BCS foram consideradas satisfatórias e seu uso foi indicado para locais sem disponibilidade de vento ou quando não é possível ou desejável a abertura de janelas.

A partir da seleção dos melhores parâmetros, os resultados comprovaram a influência do BCS em aumentar o POC e reduzir o desconforto por calor para todas as cidades analisadas. O aumento do POC em relação ao caso-base foi em média $28 \%$, com máximo de $45 \%$ nos ambientes com alta carga interna em Belo Horizonte; e média de $21 \%$, com máximo de $35 \%$ nos ambientes com baixa carga interna em Brasília. A redução do desconforto por calor foi em média $29 \%$, com máximo de $46 \%$ nos ambientes com alta carga em Belo Horizonte e média de $24 \%$ com máximo de $38 \%$ nos ambientes com baixa carga em Porto Alegre.

A renovação de ar proporcionada pelo BCS pode aumentar as horas em conforto térmico. Entretanto, ela depende de outros aspectos que são também intervenientes nas condições ambientais, tais como radiação solar incidente no BCS ou na janela, temperatura externa e temperatura interna do ambiente, densidade de carga interna - no caso deste trabalho pela ocupação -, passando pela temperatura da cavidade do BCS, que é também influenciada pelos três primeiros fatores. Como exemplo, a média mensal da renovação de ar dos ambientes da ZB1-ZB5 apresentou uma variação sazonal que inexiste nas cidades da ZB6-ZB8.

Como base nesses resultados, foi possível identificar que as zonas bioclimáticas ZB1, seguidas da ZB2, ZB3, ZB4 e ZB5, foram os locais em que o BCS apresentou maior influência em proporcionar conforto e renovação de ar, o que torna esses locais potencialmente favoráveis para a utilização do dispositivo, ao contrário de cidades de clima mais quente localizadas nas ZB6, ZB7 e ZB8.

\section{Referências}

ABREU-HARBICH; CHAVES; BRANDSTETTER. Evaluation of strategies that improve the thermal comfort and energy saving of a classroom of an institutional building in a tropical climate. Building and Environment, v. 135, p. 257-268, 2018.

AMERICAN SOCIETY OF HEATING, REFRIGERATING AND AIR-CONDITIONING ENGINEERS. Standard 55: thermal environmental conditions for human occupancy. Atlanta, 2013.

ASADI, S. et al. The effect of solar chimney layout on ventilation rate in buildings. Energy and Buildings. v. 123, p.71-78, jul. 2016.

ASSOCIAÇÃO BRASILEIRA DE NORMAS TECNICAS. NBR 15220: desempenho térmico de edificações. Rio de Janeiro, 2005.

CÂNDIDO, C.; DE DEAR, R.; LAMBERTS, R. Combined thermal acceptability and air movement assessments in a hot humid climate. Building and Environment, v. 46, p. 379-385, feb. 2011. 
CÂNDIDO, C. et al. Air movement acceptability limits and thermal comfort in Brazil's hot humid climate zone. Building and Environment, v. 45, p. 222-229, jan. 2010a.

CÂNDIDO, C. et al. Aplicabilidade dos limites da velocidade do ar para efeito de conforto em climas quentes e úmidos. Ambiente Construído, v. 10, n. 4, p. 59-68, out./dez. 2010b.

CARLO, J.; LAMBERTS, R. Development of envelope efficiency labels for commercial buildings: Effect of different variables on electricity consumption. Energy and Buildings, v. 40, p. 2002-2008, 2008.

CARLO, J.; TOCCOLINI, G.; LAMBERTS, R. Verificação das características externas de edificações em quatro capitais brasileiras. In: ENCONTRO NACIONAL DE CONFORTO NO AMBIENTE CONSTRUÍDO E ENCONTRO LATINO AMERICANO DE CONFORTO NO AMBIENTE CONSTRUÍDO, Maceió, 2005. Anais [...] Maceió: ANTAC, 2005.

COELHO, G.; GHISI, E. Correlação do consumo de energia com características construtivas e tipologias arquitetônicas de edifícios de escritórios localizados em Florianópolis. In: ENCONTRO NACIONAL, 9.; LATINO AMERICANO DE CONFORTO NO AMBIENTE CONSTRUÍDO, 5., Ouro Preto, 2007. Anais [...] Ouro Preto: ANTAC, 2007.

DE DEAR, R. et al. Progress in thermal comfort research over the last twenty years. Indoor Air, v. 23, p. 442-461, 2013.

DE DEAR, R. et al. Adaptative thermal comfort in Australian school classrooms. Building Research and Information, v. 43, p. 383-398, 2015.

HOSIEN, M.; SELIM, S. Effects of the geometrical and operational parameters and alternative outer cover materials on the performance of solar chimney used for natural ventilation. Energy and Buildings. v. 138, p. 355-367, mar. 2017.

KHANAL, R.; LEI, C. Solar chimney: a passive strategy for natural ventilation. Energy and Buildings. v. 43, p. 1811-1819, ago. 2011.

LEE, K.; STRAND, R. Enhancement of natural ventilation in buildings using a thermal chimney. Energy and Buildings, v. 41, p. 615-621, jun. 2009.

MACIEL, L. Desenvolvimento de dispositivo de proteção solar com ênfase na ventilação natural: um método de avaliação baseado em CFD. Viçosa, 2016. Dissertação (Mestrado em Arquitetura e Urbanismo) Departamento de arquitetura e Urbanismo, Universidade Federal de Viçosa, Viçosa, 2016.

MATHUR, J. et al. Experimental investigation on solar chimney for room ventilation. Solar Energy, v. 80, p. 927-935, ago. 2006.

MINISTÉRIO DE MINAS E ENERGIA. Requisitos técnicos da qualidade para o nível de eficiência energética de edifícios comerciais, de serviços e públicos. Brasília, 2010.

NASCIMENTO, L.; BARBOSA, M. Análise da influência de variáveis construtivas e de variáveis de uso e ocupação no consumo de energia em edifícios de escritório. In: ENCONTRO NACIONAL E V LATINO AMERICANO DE CONFORTO NO AMBIENTE CONSTRUÍDO, 9., Natal, 2009. Anais [...] Natal: ANTAC, 2009.

NEVES, L.; SILVA, S. Análise paramétrica de chaminés solares visando à otimização de desempenho em climas típicos do território brasileiro. Ambiente Construído. Porto Alegre, v. 17, n. 1, p. 163-182, jan./mar. 2017.

OLIVEIRA, M..; CARLO, J. Análise da qualidade da simulação do fluxo de ar de chaminés solares com o Energyplus. PARC: Pesquisa em Arquitetura e Construção. v. 9. n. 2. p. 86-98, jun. 2018.

PEREZ, I; RODRIGUEZ, A.; LOPEZ, C. Adaptive thermal comfort in the main Mexican climate conditions with and without passive cooling. Energy and Buildings, v. 145, p. 251-258, 2017.

PEREZ, Y.; CAPELUTO, I. Climatic considerations in school building design in the hot-humid climate for reducing energy consumption. Applied Energy, v. 86, p. 340-348, 2009.

SHI, L. et al. Developing an empirical model for roof solar chimney based on experimental data from various test rigs. Building and Environment, v. 110, p. 115-128, dec. 2016.

STRAUB, K. et al. Determinação da temperatura de neutralidade em salas de aula do ensino superior para as zonas bioclimáticas do estado de Mato Grosso. Ambiente Construído, Porto Alegre, v. 17, n. 1, p. 97-109, jan./mar. 2017. 
TAN, A.; WONG, N. Influences of ambient air speed and internal heat load on the performance of solar chimney in tropics. Solar Energy, v. 102, p. 116-125, abr. 2014.

ZHAI, X.; SONG, Z.; WANG, R. A review for the applications of solar chimneys in buildings. Renewable and Sustainable Energy Reviews, v. 15, p. 3757-3767, oct. 2011.

\section{Matheus Menezes Oliveira}

Departamento de Arquitetura e Urbanismo | Universidade Federal de Viçosa | Av. Peter Henry Rolfs, s/n, Campus Universitário | Viçosa MG - Brasil | CEP 36570-900 | Tel.: (31) 3612-2744 | E-mail: matheus.meneses@gmail.com

\section{Joyce Carrena Carlo}

Departamento de Arquitetura e Urbanismo | Universidade Federal de Viçosa | Tel.: (31) 3612-6021 | E-mail: joycecarlo@ufv.br

\section{Ambiente Construído}

Revista da Associação Nacional de Tecnologia do Ambiente Construído

Av. Osvaldo Aranha, $99-3^{\circ}$ andar, Centro

Porto Alegre - RS - Brasil

CEP $90035-190$

Telefone: +55 (51) 3308-4084

Fax: +55 (51) 3308-4054

www.seer.ufrgs.br/ambienteconstruido

E-mail: ambienteconstruido@ufrgs.br 